\title{
Modelling vegetation dynamics in heterogeneous pasture-woodland landscapes
}

\author{
François Gillet* \\ École Polytechnique Fédérale de Lausanne, Ecological Systems Laboratory, Station 2, 1015 Lausanne, Switzerland
}

\section{A R T I C L E I N F O}

\section{Article history:}

Received 1 May 2005

Accepted 26 May 2008

Published on line 4 July 2008

Keywords:

Cattle selectivity

Climate change

Landscape diversity

Landscape dynamics

Silvopastoral ecosystems

Spatial heterogeneity

Vegetation

\begin{abstract}
A B S T R A C T
Recent knowledge about tree regeneration, shifting mosaic in the herb layer or complex interactions between cattle activities, vegetation and landscape structure has allowed the development of a novel, spatially explicit, mosaic compartment model of the dynamics of silvopastoral ecosystems (WoodPAM). This deterministic model considers three hierarchical levels: the focal level is the phytocoenosis, represented by a cell or a patch in the landscape with a variable local stock density; herb and shrub communities as well as size-structured tree populations are the components of each patch at the lower level, spatially implicit; patches are aggregated in a pastoral management unit building the higher level, with an externally controlled global stock density.

Simulation experiments were applied to a pasture-woodland landscape in order to assess the consequences of hierarchically organized ecological interactions on spatio-temporal patterns of vegetation and cattle habitat use. In the first scenario, the global environmental and management conditions were fixed to their observed initial values. The patterns of vegetation and cattle habitat use evolved at very long term toward a permanent state dominated by wood-pastures, strongly dependent on the spatial configuration of the environment. Landscape dynamics being very slow, the second scenario took into account the effect of climate change, by considering a linear increase of the annual temperature, which influenced forage production and the speed of vegetation dynamics. In this simulation, closed forests and densely wooded pastures tended to dominate, vegetation diversity decreased, the patterns became unstable and long-period cyclic successions appeared at patch level.

Model simulations emphasized the role of livestock selectivity to preserve vegetation variability and heterogeneity at long term. A high selectivity occurs at low overall stocking rate, inducing a slow fragmentation of the landscape into open pastures and closed forests and a decline of wood-pastures. A low selectivity occurs at high utilization rates, decreasing the heterogeneity of the landscape.

These results are discussed in the light of the recent theories binding grazing ecology and woodland dynamics.
\end{abstract}

(c) 2008 Elsevier B.V. All rights reserved.

\section{Introduction}

Pasture-woodlands are traditional multiuse landscapes in European mountains, especially in Switzerland (Etienne,
1996). They result from a long history of past management. Vegetation ranges from open grassland to closed forests, including wood-pastures with scattered or clumped trees (Gillet and Gallandat, 1996a, b).

* Tel.: +41 2169337 45; fax: +41 216933913 .

E-mail address: francois.gillet@epfl.ch. 


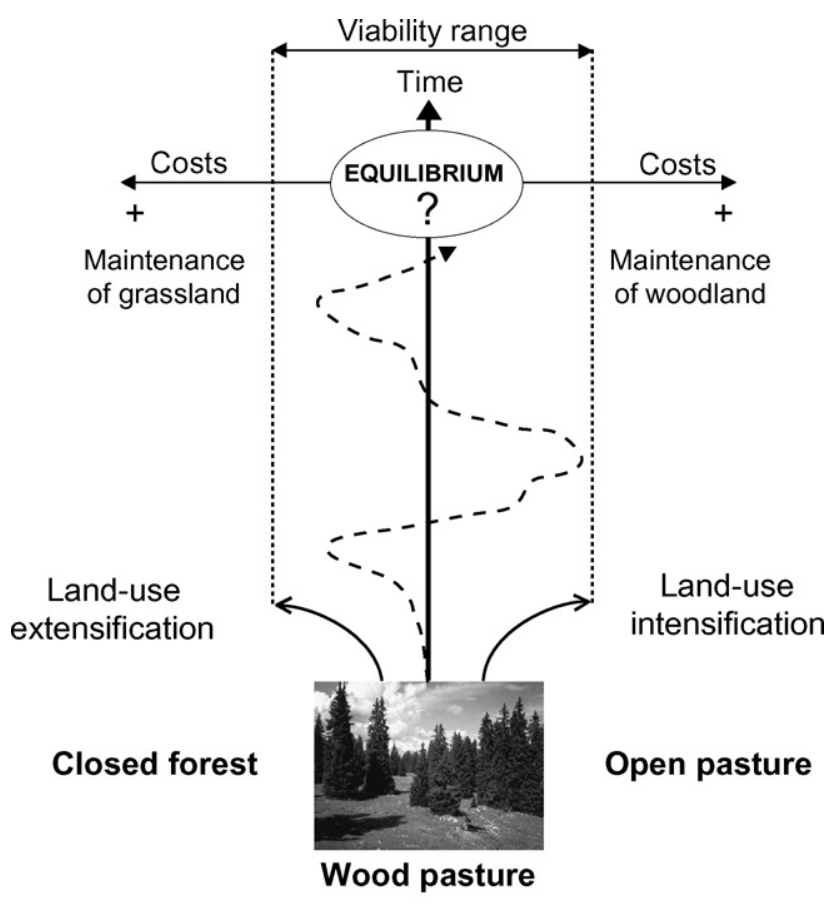

Pasture-woodland landscape

Fig. 1 - Wood-pasture dynamics in a pasture-woodland landscape.

A wood-pasture is not a simple ecotone or interface between closed forests and open pastures. In such a silvopastoral ecosystem, grassland and woodland are intimately associated as the result of a balance between divergent ecological processes (Gillet et al., 2002).

Cohabitation of pasture and woodland in a single and diverse silvopastoral ecosystem is not easy to preserve. Both intensification and extensification of land use may lead to break down this precarious association (Fig. 1). Such historical segregation of woodland and grassland has been observed in many places in the Jura mountains (Barbezat, 2002) and is still a serious threat on wood-pastures. The recovery of a wood-pasture either from a closed forest or an open pasture is not likely to occur without heavy and expensive human interventions. Understanding dynamic processes at work in pasture-woodland is necessary to maintain ecosystem goods and services at a lowest cost.

In grazed areas with a homogeneous abiotic environment, livestock activities are the main factor that controls plant and animal community dynamics. One of the new functions the society asks to the domestic herbivores is to maintain or improve the biodiversity and the integrity of pastoral or silvopastoral landscapes (Balent et al., 1998). Until little time ago, a shortage of basic knowledge characterized the relationships between grazing activities and vegetation especially at landscape level. They involve different levels of organization either in the case of free ranging animals or when feeding and spatial behaviour of grazing animals is under human control. Moreover, landscape structure may have a strong influence on these relationships, especially in mountain areas (Kohler et al., 2006).

\subsection{Hierarchical organization of silvopastoral ecosystems}

Hierarchy theory is a powerful framework to describe silvopastoral ecosystems (O'Neill et al., 1986; Wu and David, 2002). Different nested levels of organization can be recognized in the vegetation of pasture-woodlands (Gillet and Gallandat, 1996a). At landscape level, one observes a zonation or a mosaic of phytocoenoses, ranging from unwooded pastures to grazed or ungrazed forests. Each phytocoenosis is itself a complex system of elementary plant communities, i.e. moss, herb, shrub and tree synusiae. Each synusia is an assemblage of organisms belonging to a limited pool of species or plant functional groups.

Each entity or process we can consider in a silvopastoral ecosystem has a characteristic spatial and temporal scale (Fig. 2). Landscape dynamics is the result of processes acting in a limited domain of scale. To model this dynamics, one needs to describe interactions between cattle and vegetation at medium scale (e.g. tree regeneration, successions of synusiae) as well as at large scale (pastoral management, successions of phytocoenoses).

\subsection{Modelling long-term vegetation dynamics}

Landscape dynamics in wooded areas is very slow: time series are not likely to be available for long-term analysis. A modelling approach could help at understanding the complex organizational and dynamic processes involved. For this purpose, I have first developed a spatially implicit model of vegetation dynamics in wooded pastures, PATUMOD, which has been successfully used as a decision tool in management projects (Gillet et al., 2002).

However, this relatively simple model suffered from several limitations and had to be improved. Recent studies reported the importance of spatial heterogeneity on the segregation of cattle activities (Kohler et al., 2006). Therefore, a spatially explicit model, taking into account the distinct grazing, dunging and trampling patterns, was necessary. Moreover, PATUMOD focused on vegetation dynamics at the level of a local phytocoenosis, so that landscape characteristics, such as overall forage production, acted as external constraints and were assumed to be constant: local dynamics at patch level did not influence global dynamics at landscape level, leading to unrealistic long-term predictions. A landscape simulation model (Costanza and Voinov, 2004), using a mosaic of spatial cells, is a good solution to this problem: in each cell (raster or polygon), a compartment model describes local dynamics; the cells can then be connected by horizontal fluxes of material and information.

Finally, long-term predictions of vegetation dynamics might consider the highly probable effects of climate change in the future (Rebetez, 1999). The most recent models of global warming predict that the mean annual temperature will increase of about $4{ }^{\circ} \mathrm{C}$ per century in Switzerland (M. Rebetez, personal communication, 2005).

By taking account the knowledge recently acquired on tree regeneration, shifting mosaic in the herb layer (Kohler et al., 2004) or complex interactions between cattle activities, vegetation and landscape structure (Kohler et al., 2006), I developed 


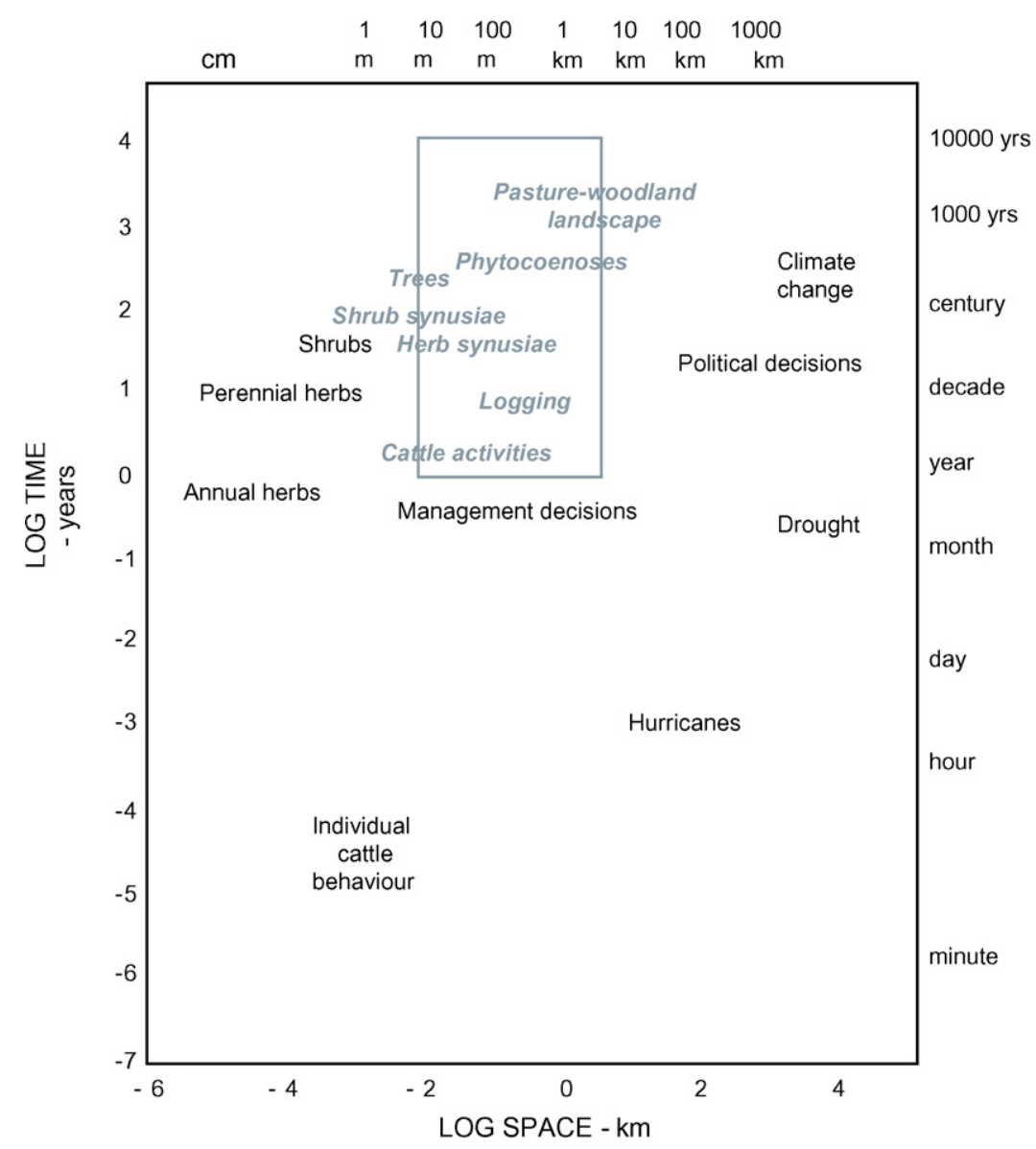

Fig. 2 - Space and time scales in which objects or processes occur in silvopastoral ecosystems: spatial extent and characteristic time constant of plants, plant communities, cattle interactions, human influences or climatic processes. Grey rectangle and items: scale domain, objects and processes to be considered in a model of landscape dynamics.

a novel, spatially explicit, mosaic compartment model of the dynamics of silvopastoral ecosystems, called WooDPAM. This model was implemented in the Simile 4.3 modelling environment (Muetzelfeldt and Massheder, 2003).

\subsection{Model objectives}

The main purpose of the mosaic model was to assess the consequences of hierarchically organized ecological interactions on the spatio-temporal patterns of vegetation and cattle habitat use at medium and large scale. This strategic model should be general enough to be applied to various artificial and natural landscapes. It should address the following questions, which have important theoretical and practical implications: (1) What are the main driving forces of vegetation heterogeneity in this hierarchical system? (2) Are there locally multiple attractors for the state variables, such as tree cover or local livestock density? (3) Is there any attractor for the spatial configuration of vegetation and cattle activity if environmental and management conditions are fixed, including the overall stocking rate? (4) What is the effect of climate change on longterm landscape dynamics?

In this paper, I present the structure of the model and the first results obtained from simulation experiments.

\section{Methods}

\subsection{Model structure: the mosaic model}

WooDPAM is a purely deterministic model with differential and algebraic equations. Three hierarchical levels are considered but only two are spatially explicit. (1) The focal level is the phytocoenosis, represented by a cell or a patch in the landscape with a variable local stock density. (2) Herb and shrub synusiae as well as size-structured tree populations are the components of each patch at the lower level, spatially implicit. (3) Patches are aggregated in a pastoral management unit building the higher level, with an externally controlled global stock density. At the chosen time resolution of 1 year, interactions between neighbouring patches are not considered, except for seedling recruitment. However, local patch dynamics influence some global constraints at the upper level, so that dynamics in a single patch is depending on the evolution of all patches in the landscape mosaic.

In the Simile environment, the patch submodel representing the focal level is disaggregated into a mosaic model at the landscape level. The landscape is represented by a mosaic of $n$ cells or patches $i$, without any explicit topology. Interactions between neighbouring patches are neglected, except in 
Table 1 - Parameters of the WoodPAM model

\begin{tabular}{|c|c|c|c|c|}
\hline Variable & Value & Unit & Description & Source \\
\hline AG & 0.6 & ${ }^{\circ} \mathrm{C}(100 \mathrm{~m})^{-1}$ & Elevation lapse rate for mean annual temperature & Pauli et al., 1996 \\
\hline$b$ & -0.005 & - & Shape coefficient for altitude effect & Gillet et al., 2002 \\
\hline $\mathrm{bF}$ & 0.3 & $\mathrm{y}^{-1}$ & Minimal transformation rate into fallow if no shrub & Gillet et al., 2002 \\
\hline $\mathrm{bp}$ & {$[2,0.5,0.75]$} & - & Resistance to browsing - [Picea, Acer, Fagus] & $\begin{array}{l}\text { Béguin and Vandenberghe, } \\
\text { unpublished }\end{array}$ \\
\hline bS & 0.2 & $\mathrm{y}^{-1}$ & Maximal recruitment rate of shrubs & Gillet et al., 2002 \\
\hline c & 1080 & m a.s.l. & Half-saturation coefficient for altitude effect & Gillet et al., 2002 \\
\hline$d$ & -0.0133 & - & Shape coefficient for grazing pressure & Gillet et al., 2002 \\
\hline $\mathrm{DD}$ & 8 & $A B U^{-1} d^{-1}$ & Daily dung deposition & Kohler et al., 2006 \\
\hline dwt & 500 & $\mathrm{~m}$ & Half-saturation distance to water & Optimization \\
\hline fc & 18 & $\operatorname{kgDMABU} \mathrm{A}^{-1} \mathrm{~d}^{-1}$ & Daily forage consumption of a dairy cow & Gillet et al., 2002 \\
\hline fpi & 8.5 & tDM ha ${ }^{-1} y^{-1}$ & Initial forage production & Regression \\
\hline fpm & 20 & tDM ha $a^{-1} y^{-1}$ & Maximal forage production & Regression \\
\hline ls & {$[0.5,0.2,0.8]$} & - & Tolerance to shade - [Picea, Acer, Fagus] & $\begin{array}{l}\text { Landolt, 1977; Ellenberg et } \\
\text { al., } 1991\end{array}$ \\
\hline maSn & 40 & $\mathrm{y}$ & $\begin{array}{l}\text { Maximal time constant of shrubs without stress (no } \\
\text { browsing, no shade) }\end{array}$ & Optimization \\
\hline maSs & 10 & $\mathrm{y}$ & $\begin{array}{l}\text { Minimal time constant of shrubs under stress } \\
\text { conditions (browsing or/and shading) }\end{array}$ & Optimization \\
\hline maThs & {$[25,4,6]$} & $\mathrm{y}$ & $\begin{array}{l}\text { Maximal transit time of saplings in the herb layer - } \\
\text { [Picea, Acer, Fagus] }\end{array}$ & $\begin{array}{l}\text { Béguin and Vandenberghe, } \\
\text { unpublished }\end{array}$ \\
\hline maTst & {$[100,20,30]$} & $\mathrm{y}$ & $\begin{array}{l}\text { Maximal transit time of saplings in the shrub layer- } \\
\text { [Picea, Acer, Fagus] }\end{array}$ & $\begin{array}{l}\text { Béguin and Vandenberghe, } \\
\text { unpublished }\end{array}$ \\
\hline maTt & {$[150,150,150]$} & $\mathrm{y}$ & $\begin{array}{l}\text { Average survival time of a tree without competition - } \\
\text { [Picea, Acer, Fagus] }\end{array}$ & Béguin, unpublished \\
\hline mdd & 2000 & $\mathrm{ha}^{-1}$ & Maximal observed dung density & Kohler et al., 2006 \\
\hline miThs & {$[5,2,3]$} & $\mathrm{y}$ & $\begin{array}{l}\text { Minimal transit time in the herb layer - [Picea, Acer, } \\
\text { Fagus] }\end{array}$ & $\begin{array}{l}\text { Béguin and Vandenberghe, } \\
\text { unpublished }\end{array}$ \\
\hline miTst & {$[15,10,15]$} & $\mathrm{y}$ & $\begin{array}{l}\text { Minimal transit time in the shrub layer - [Picea, Acer, } \\
\text { Fagus] }\end{array}$ & $\begin{array}{l}\text { Béguin and Vandenberghe, } \\
\text { unpublished }\end{array}$ \\
\hline miTt & {$[80,70,100]$} & $\mathrm{y}$ & $\begin{array}{l}\text { Average survival time of a tree with competition - } \\
\text { [Picea, Acer, Fagus] }\end{array}$ & Béguin, unpublished \\
\hline $\mathrm{msc}$ & 0.8 & $(\%)$ & $\begin{array}{l}\text { Maximal proportion of non-browsed saplings } \\
\text { (whenever their cover is } 100 \% \text { ) }\end{array}$ & Optimization \\
\hline PVF & 10 & - & Average pastoral value of fallow (0-100) & Gillet et al., 2002 \\
\hline PVL & 20 & - & Average pastoral value of lawn (0-100) & Gillet et al., 2002 \\
\hline PVM & 40 & - & Average pastoral value of meadow (0-100) & Gillet et al., 2002 \\
\hline PVU & 5 & - & Average pastoral value of underwood (0-100) & Gillet et al., 2002 \\
\hline pwm & 0.5 & - & Maximal value of the water effect (0-1) & Optimization \\
\hline$R$ & {$[20,10,100]$} & - & $\begin{array}{l}\text { Reducer of sapling recruitment from external sources } \\
\text { - [Picea, Acer, Fagus] }\end{array}$ & Béguin, unpublished \\
\hline ra & 0.00002152 & - & Effect of altitude on forage production & Regression \\
\hline rFL & 0.1 & $\mathrm{y}^{-1}$ & Maximal $F$ to $L$ transformation rate & Gillet et al., 2002 \\
\hline $\mathrm{rFM}$ & 0.4 & $\mathrm{y}^{-1}$ & Maximal $F$ to $M$ transformation rate & Gillet et al., 2002 \\
\hline rLF & 0.5 & $\mathrm{y}^{-1}$ & Maximal $L$ to $F$ transformation rate & Gillet et al., 2002 \\
\hline rLM & 0.06 & $\mathrm{y}^{-1}$ & Maximal $L$ to $M$ transformation rate & Gillet et al., 2002 \\
\hline $\mathrm{rm}$ & 0.05 & - & Maximal rate of forage production & Regression \\
\hline rMF & 0.8 & $\mathrm{y}^{-1}$ & Maximal $M$ to $F$ transformation rate & Gillet et al., 2002 \\
\hline rML & 0.05 & $\mathrm{y}^{-1}$ & Maximal $M$ to $L$ transformation rate & Gillet et al., 2002 \\
\hline Rt & {$[3,9,6]$} & $\mathrm{y}^{-1}$ & Recruitment rate of saplings - [Picea, Acer, Fagus] & Optimization \\
\hline rTh & 0.001 & $10^{2} \mathrm{~m}$ & Radius of a single seedling & Béguin, unpublished \\
\hline rTs & 0.005 & $10^{2} \mathrm{~m}$ & Radius of a single sapling & Béguin, unpublished \\
\hline $\mathrm{rTt}$ & 0.016 & $10^{2} \mathrm{~m}$ & Radius of a single tree & Béguin, unpublished \\
\hline slt & 40 & $\circ$ & Slope threshold & Optimization \\
\hline spm & 1 & - & Maximal value of the selectivity parameter if $\mathrm{GU}=0$ & Optimization \\
\hline sps & 2.5 & - & Shape parameter for cattle selectivity & Optimization \\
\hline tls & 5 & $\mathrm{y}$ & Time lag for shrub recruitment & Gillet et al., 2002 \\
\hline um & 0.0001 & $\mathrm{y}^{-1}$ & Minimum $U$ to $F$ transformation rate if $F=0$ & Optimization \\
\hline
\end{tabular}

Brackets indicate arrays of parameters used for tree species. 
the case of a regular grid of square cells for which the von Neumann connectivity is applied to calculate inflows of tree seedlings from the eight adjacent cells. Spatial boundaries (fences) impose constraints on local cattle density.

Internal patch dynamics is dependent on local environment and global constraints. The spatial influence of management structures is taken into account by considering the distance DW (m) from the centre of each patch to the nearest watering place.

The mosaic model considers the spatially structured environment of the landscape by specifying the area LA (ha), the average altitude $A$ ( $m$ a.s.l.), the average slope SL $\left({ }^{\circ}\right)$ and the proportion of rock outcrops RO for every patch. Patch area LA usually ranges between $1 / 100$ and $1 / 16$ ha.

An apparent altitude AA is considered for calculating the altitude effect $\mathrm{AE}$ influencing forage production and vegetation dynamics in each patch. This apparent altitude takes into account the increase of temperature due to climate change by simply applying an elevation shift proportional to an average annual warming CC with an elevation lapse rate AG of $0.6^{\circ} \mathrm{C}$ per $100 \mathrm{~m}$ elevation (Pauli et al., 1996); time represents here the number of years after the beginning of the simulation:

$\mathrm{AA}_{i}=\mathrm{A}_{i}-\min \left(\frac{\text { time CC }}{\mathrm{AG}}, \mathrm{A}_{i}\right)$.

The apparent altitude linearly decreases through time from the actual altitude $A$ to 0 , but cannot become less than 0 . Note that annual variability is not taken into account, even if it could be easy to add stochasticity in Eq. (1). The altitude effect $\mathrm{AE}$, ranging from 0 to 1 , is a sigmoid function of the apparent altitude, with two parameters (see Table 1 for a description of all model parameters):

$\mathrm{AE}_{i}=\frac{\exp \left(b\left(\mathrm{AA}_{i}-c\right)\right)}{\exp \left(b\left(\mathrm{AA}_{\mathrm{i}}-\mathrm{c}\right)\right)+1}$

In each patch, vegetation is represented by two submodels: a 'herb' submodel including four compartments, and a 'wood' submodel with four compartments for shrubs and trees. These vegetation submodels are linked to a third 'cattle' submodel with various local variables influencing and being influenced by vegetation dynamics.

The diversity of the vegetation is measured using Shannon's index applied to synusiae at patch level or phytocoenoses at landscape level.

\subsection{The herb submodel}

The herb submodel enclosed in the patch submodel is composed of four compartments, representing the aboveground cover of each herbaceous homoecy. Homoecies are synusia types based on physiognomical and functional criteria (Gillet et al., 2002). They are interconnected by flows representing temporal transformations. These compartments are: L (oligotrophic lawns): short swards and heaths with low productivity and low pastoral value; $M$ (eutrophic grazed meadows): fertilized pastures with high productivity and high pastoral value; F (fallows): tall communities of forbs and grasses, not or little grazed; $U$ (underwood herbaceous communities): understorey herb and heath communities. Fal- lows play an important integrating role by ensuring the dynamic link between the grassland and the woodland subsystems.Changes in the herb compartments are controlled by four differential equations:

$$
\begin{aligned}
& \frac{\mathrm{dL}_{\mathrm{i}}}{\mathrm{dt}}=\mathrm{MtoL}_{\mathrm{i}}-\mathrm{LtoM}_{\mathrm{i}}+\mathrm{FtoL}_{\mathrm{i}}-\mathrm{LtoF}_{i}, \\
& \frac{\mathrm{dM}_{\mathrm{i}}}{\mathrm{dt}}=\mathrm{LtoM}_{\mathrm{i}}-\mathrm{MtoL}_{\mathrm{i}}+\mathrm{FtoM}_{\mathrm{i}}-\mathrm{MtoF}_{i}, \\
& \frac{\mathrm{dF}}{\mathrm{dt}}=\mathrm{LtoF}_{\mathrm{i}}-\mathrm{FtoL}_{i}+\mathrm{MtoF}_{i}-\mathrm{FtoM}_{i}+\mathrm{UtoF}_{i}-\mathrm{FtoU}_{i}, \\
& \frac{\mathrm{d} U_{i}}{\mathrm{dt}}=\mathrm{FtoU}_{i}-\mathrm{UtoF}_{i} .
\end{aligned}
$$

Flows between compartments are influenced by cattle activities, i.e. grazing intensity GI, dunging intensity DI and trampling intensity TI (see detailed description in Section 2.5), as well as by local and global environmental variables (see Table 1 for a description of all model parameters):

$$
\begin{aligned}
& \mathrm{MtoL}_{\mathrm{i}}=\mathrm{rML} \mathrm{M}_{\mathrm{i}}\left(1-\mathrm{DI}_{\mathrm{i}}\right) \text {, } \\
& \mathrm{LtoM}_{\mathrm{i}}=\mathrm{rLML}_{\mathrm{i}} \mathrm{DI}_{\mathrm{i}}, \\
& \mathrm{FtoL}_{\mathrm{i}}=\mathrm{rFLF}_{\mathrm{i}} \mathrm{GI}_{\mathrm{i}}\left(1-\mathrm{DI}_{\mathrm{i}}\right) \text {, } \\
& \mathrm{LtoF}_{i}=\mathrm{rLF}_{\mathrm{i}}\left(1-\mathrm{GI}_{\mathrm{i}}\right)\left(1-\mathrm{TI}_{\mathrm{i}}\right) \min \left(1, \mathrm{bF}+\mathrm{Sc}_{\mathrm{i}}\right) \mathrm{AE}_{\mathrm{i}}, \\
& \mathrm{FtoM}_{\mathrm{i}}=\mathrm{rFMF}_{\mathrm{i}} \mathrm{GI}_{\mathrm{i}} \mathrm{DI}_{\mathrm{i}} \text {, } \\
& \text { MtoF }_{i}=\mathrm{rMF} \mathrm{M}_{\mathrm{i}} \mathrm{DI}_{i}\left(1-\mathrm{GI}_{\mathrm{i}}\right)\left(1-\mathrm{TI}_{\mathrm{i}}\right) \min \left(1, \mathrm{bF}+\mathrm{Sc}_{\mathrm{i}}\right) \text {, } \\
& \text { FtoU }_{i}=F_{i} \text { Ttc }_{\bullet}, i \\
& \mathrm{UtoF}_{i}=U_{i}\left(F_{i}+\mathrm{um}\right) \text {. }
\end{aligned}
$$

These equations result from the improvement of the corresponding equations in PATUMOD, based on the knowledge of transformation processes obtained from recent experimental studies on grassland dynamics in wooded pastures (Kohler et al., 2004). The sum of $L_{i}, M_{i}, F_{i}$ and $U_{i}$ is constant for a given patch $i$ and is equal to $1-\mathrm{RO}_{i}$, where $\mathrm{RO}_{i}$ is the constant proportion of rock outcrops in the patch area. This relation assumes that bare soil is rapidly colonized by herbaceous vegetation.

\subsection{The wood submodel}

The wood submodel inside the patch submodel describes the dynamics of several tree populations by a chain of three compartments corresponding to the critical stages of tree growth: Th: number of seedlings (more than 2 years old) and saplings exposed to grazing and browsing in the herb layer (height $<40 \mathrm{~cm}$ ); Ts: number of saplings exposed to browsing in the low shrub layer $(40-150 \mathrm{~cm})$; Tt: number of trees in the high shrub layer and in the tree layer (height $>150 \mathrm{~cm}$ ), having escaped or resisted browsing. In fact, these compartments are arrays of state variables representing continuous densities of the three most common tree species in wood-pastures: Norway 
spruce (Picea abies) is widespread in wooded pastures, due to its great resistance to browsing, to its tolerance to shade and its dispersion facility; sycamore maple (Acer pseudoplatanus) is a common post-pioneer species with a high potential of regeneration, but a low tolerance to browsing and shade, and thus rarely dominant; European beech (Fagus sylvatica) is the most competitive species in European forests, with a limited seed dispersion, a limited resistance to browsing but a great tolerance to shade, and is sometimes dominant in densely wooded pastures. These three species can be observed in a wide range of climatic and edaphic conditions.

A fourth compartment describes shrub dynamics, S: cover of the shrub species (mainly thorny shrubs playing an important protecting role in the tree regeneration process, such as Rosa or Crataegus species) above the herb layer.

Auxiliary variables were added to represent, for every tree species $s$ and in each patch $i$, the cover of trees $\mathrm{Ttc}_{\mathrm{s}, \mathrm{i}}$, of saplings in the shrub layer $\mathrm{Tsc}_{\mathrm{s}, \mathrm{i}}$, and of saplings in the herb layer $\mathrm{Thc}_{\mathrm{s}, \mathrm{i}}$ :

$\mathrm{Ttc}_{\mathrm{s}, i}=\frac{\mathrm{Tt}_{\mathrm{s}, i} \pi \mathrm{rTt}^{2}}{1.1 \mathrm{LA}_{\mathrm{i}}}$

$\operatorname{Tsc}_{s, i}=\frac{\mathrm{Ts}_{s, i} \pi \mathrm{rss}^{2}}{1.1 \mathrm{LA}_{\mathrm{i}}}$

$\operatorname{Thc}_{s, i}=\frac{\operatorname{Th}_{s, i} \pi \mathrm{rh}^{2}}{1.1 \mathrm{LA}_{\mathrm{i}}}$

Calculations of Ttc, Tsc and Thc consider an average crown radius (rTt, rTs or $\mathrm{rTh}$ ), the same for all species, and a crown overlap of $10 \%$. The total tree cover in a patch $\mathrm{Ttc}_{, i}$ is the sum of the species-specific tree covers $\mathrm{Ttc}_{\mathrm{s}, \mathrm{i}}$.

Vegetation openness in the neighbourhood of the cell is known to be an important predictor of cattle frequentation (Kohler et al., 2006). It is here calculated from the average tree cover in a window around the patch, including all neighbouring cells within the paddock $(k \leq 9)$ :

$\mathrm{VO}_{i}=1-\frac{\mathrm{Ttc}_{\bullet, i}+\sum_{j=1}^{k} \mathrm{Ttc}_{\bullet}, j}{1+k}$

The overall shrub cover Sc is also calculated, including shrub and all tree species:

$\mathrm{Sc}_{i}=\mathrm{S}_{\mathrm{i}}+\mathrm{Tsc}_{\bullet}, \mathrm{i}$

Changes in the wood compartments are controlled by four differential equations:

$$
\begin{aligned}
& \frac{d \mathrm{Th}_{s, i}}{\mathrm{dt}}=\mathrm{inTh}_{\mathrm{s}, \mathrm{i}}-\operatorname{exTh}_{\mathrm{s}, \mathrm{i}}-\operatorname{ThtoTs}_{\mathrm{s}, \mathrm{i}}, \\
& \frac{\mathrm{dTs}_{\mathrm{s}, \mathrm{i}}}{\mathrm{dt}}=\operatorname{ThtoTs}_{\mathrm{s}, \mathrm{i}}-\operatorname{exTs}_{\mathrm{s}, \mathrm{i}}-\mathrm{TstoTt}_{\mathrm{s}, \mathrm{i}}, \\
& \frac{\mathrm{dTt}_{\mathrm{s}, \mathrm{i}}}{\mathrm{dt}}=\mathrm{TstoTt}_{\mathrm{s}, \mathrm{i}}-\mathrm{exTt}_{\mathrm{s}, \mathrm{i}}, \\
& \frac{\mathrm{d} \mathrm{S}_{\mathrm{i}}}{\mathrm{dt}}=\mathrm{dSi} \mathrm{i}_{i}-\mathrm{dSo}_{i}
\end{aligned}
$$

The recruitment inflow of new saplings of a tree species $s$ depends on the number of trees of the same species in the patch $i$ and in its $k$ neighbouring cells inside the paddock:

$\operatorname{inTh}_{s, i}=\mathrm{Rt}_{s}\left(\mathrm{Tt}_{\mathrm{s}, \mathrm{i}}+\frac{8}{\mathrm{k}} \frac{\sum_{j=1}^{k} \mathrm{Tt}_{\mathrm{s}, j}}{\mathrm{R}_{\mathrm{s}}}\right)\left(U_{\mathrm{i}}+F_{\mathrm{i}}+\mathrm{RO}_{\mathrm{i}}\right)$.

The parameter $R_{S}$ controls the diffusion rate of propagules from the trees in the neighbouring cells, whereas $R t_{s}$ is the average number of seedlings produced by every tree and having reached the age of 2 years. The model assumes that sapling recruitment can only occur in underwoods, fallows or on rock outcrops.

The death rate of small saplings depends on the browsing intensity for the species in the herb layer BIh, on the total tree cover and on three species-specific parameters:

$\operatorname{exTh}_{s, i}=\min \left(1, \frac{1}{\operatorname{maThs}_{s}}+\frac{\operatorname{BIh}_{s, i}+\left(1-l s_{s}\right) \operatorname{Ttc}_{\bullet}^{2}}{\text { miThs }_{s}}\right) \operatorname{Th}_{s, i}$

Transitional growth from Th to Ts is limited by shrub cover (carrying capacity of the shrub layer), total tree cover (light availability), browsing intensity in the herb layer and altitude:

$$
\begin{aligned}
\text { ThtoTs }_{s, i}= & \frac{\operatorname{Th}_{s, i}}{\max \left(\text { miThs }_{s}, \text { maThs }_{s} \cdot \mathrm{BIh}_{\mathrm{s}, i}\right)}\left(1-\mathrm{Sc}_{\mathrm{i}}\right) \\
& \times\left(1-\left(1-\mathrm{ls}_{\mathrm{s}}\right) \mathrm{Ttc}_{\bullet, i}^{2}\right)\left(1-\mathrm{BIh}_{\mathrm{s}, \mathrm{i}}\right) \mathrm{AE}_{i} .
\end{aligned}
$$

These two last flows are controlled by the same three parameters for each species: maThs $s_{s}$ is the average transit time or survival time of saplings in the herb layer without browsing; miThs $_{s}$ is their average transit time or survival time when browsed; $1 s_{s}$ is the tolerance to shade of the young trees, between 0 (heliophilous) and 1 (sciaphilous), adapted from the light indicator values (Landolt, 1977; Ellenberg et al., 1991).

The death rate of tall saplings depends on browsing intensity in the shrub layer BIs and on total tree cover:

$\operatorname{exTs}_{s, i}=\min \left(1, \frac{1}{\text { maTst }_{s}}+\frac{\mathrm{BIs}_{s, i}+\left(1-\mathrm{ls}_{s}\right) \mathrm{Ttc}_{\bullet, i}^{2}}{\text { miTst }_{\mathrm{s}}}\right) \mathrm{Ts}_{s, i}$

Transitional growth from Ts to Tt is limited by total tree cover, browsing intensity in the shrub layer and altitude:

TstoTt $_{s, i}=\frac{\text { Ts }_{s, i}}{\max \left(\text { miTst }_{s}, \text { maTst }_{s} \cdot \text { BIs }_{s, i}\right)}\left(1-\right.$ Ttc $\left._{\bullet}, i\right)\left(1-\right.$ BIs $\left._{s, i}\right) A E_{i}$.

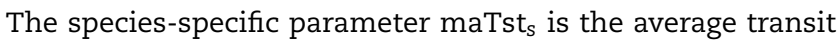
time or survival time of saplings in the shrub layer without browsing; miTst $_{s}$ is their average transit time or survival time when browsed.

The death rate of trees depends on total tree cover and on two species-specific parameters:

$\operatorname{exTt}_{s, i}=\left(\frac{1}{\operatorname{maTt}_{\mathrm{s}}}+\frac{\mathrm{Ttc}_{\bullet}, \mathrm{i}}{\mathrm{miTt}_{\mathrm{s}}}\right) \mathrm{Tt}_{\mathrm{s}, \mathrm{i}}$ 


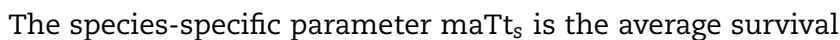
time of the trees without competition; miTt $_{s}$ is the average survival time of the trees undergoing competition (when tree cover is $100 \%$ ).

Shrub dynamics depends on two flows (Eq. (23)). The inflow represents shrub recruitment and is depending on the local grazing intensity, on the proportion of rock outcrops, fallows and underwoods (with a delay of tlS $=5$ years) and on the altitude effect:

$\mathrm{dSi} \mathrm{i}_{\mathrm{i}}=\mathrm{bS}$ delay $\left(\left(\mathrm{RO}_{\mathrm{i}}+F_{\mathrm{i}}+\frac{\mathrm{U}_{\mathrm{i}}}{2}\right)\left(1-\mathrm{GI}_{\mathrm{i}}\right), \mathrm{tlS}\right)\left(1-\mathrm{Sc}_{\mathrm{i}}\right) \mathrm{AE}_{\mathrm{i}}$.

The outflow quantifies the decay of shrubs, its rate depending on the local stock density and on the tree cover:

$\mathrm{dSo}_{i}=\min \left(1, \max \left(\mathrm{mSn}, \operatorname{mSs}\left(\left(1-\exp \left(\mathrm{dLSD}_{i}\right)\right)^{2}+\mathrm{Ttc}_{\bullet}, i\right)\right)\right) \mathrm{S}_{\mathrm{i}}$.

\subsection{The cattle submodel: stock density and carrying capacity}

At the paddock level, the global stock density GSD is a control parameter expressed in $\mathrm{ABU} \mathrm{d} \mathrm{ha}^{-1} \mathrm{y}^{-1}$. One Adult Bovine Unit (ABU) is equivalent to one dairy cow of $600 \mathrm{~kg} \mathrm{LW}$. GSD is calculated from the overall cattle load in the paddock GS (ABU), the grazing duration GD (the total number of days per year that cattle graze in the paddock, expressed in $\mathrm{dy}^{-1}$ ) and the paddock area (the sum of all $n$ patch areas LA, expressed in ha):

$\mathrm{GSD}=\frac{\mathrm{GS} G D}{\sum_{i=1}^{n} \mathrm{LA}_{i}}$

At the patch level, the local pastoral value LPV is calculated from the cover of herb synusiae (Gillet et al., 2002) and is
$\mathrm{LPV}=0\left(\mathrm{tDM} \mathrm{ha} \mathrm{a}^{-1} \mathrm{y}^{-1}\right), \mathrm{rm}$ the maximal rate of forage production for $\mathrm{AA}=0$, and ra the slope of the altitude effect on forage production.

At the paddock level, the global stock density is externally fixed but the global carrying capacity GCC, expressed in $\mathrm{ABU} \mathrm{dha}^{-1} \mathrm{y}^{-1}$ as well, varies over years depending on the total forage production. GCC is calculated from the total annual local forage production in all $n$ patches $i$ and a daily forage consumption fc of $18 \mathrm{~kg}$ DM per ABU, including losses:

$\mathrm{GCC}=\frac{\sum_{i=1}^{n} \mathrm{LFP}_{i}}{\mathrm{fC} \sum_{i=1}^{n} \mathrm{LA}_{i}}$

The global pastoral value GPV is the weighted mean of the local pastoral value of all patches:

$\mathrm{GPV}=\frac{\sum_{i=1}^{n}\left(\mathrm{LPV}_{i} \mathrm{LA}_{i}\right)}{\sum_{i=1}^{n} \mathrm{LA}_{i}}$

The global utilization rate GU measures the proportion of consumed forage in the whole paddock and is calculated as the ratio between the global stock density and the global carrying capacity:

$\mathrm{GU}=\frac{\mathrm{GSD}}{\mathrm{GCC}}$.

The local carrying capacity LCC represents the maximal stock density allowed by the local forage production in the patch:

$\mathrm{LCC}_{i}=\frac{\mathrm{LFP}_{i}}{\mathrm{fC} \mathrm{LA}_{i}}$

The local stock density LSD is proportional to the global stock density GSD, and limited by the slope, the distance to water, rock outcrops, the vegetation openness, the local tree cover and the ratio between local and global carrying capacities. These limiting factors of the patch frequentation by livestock are expressed as multipliers to get a first estimate of the local stock density LSD1:

$$
\mathrm{LSD}_{i}=\mathrm{GSD}\left(\left(1-\frac{\min \left(\mathrm{SL}_{i}, \mathrm{slt}\right)}{\mathrm{slt}}\right) \frac{1}{1+\mathrm{DW}_{\mathrm{i}} / \mathrm{dwt}}\left(1-\mathrm{RO}_{i}\right) \mathrm{VO}_{i}^{2}\left(1-\mathrm{Ttc}_{\bullet}, \mathrm{i}\right)^{2} \frac{\mathrm{LCC}_{\mathrm{i}}}{\mathrm{GCC}}\right)^{\mathrm{SP}}
$$

used for the calculation of the annual local forage production LFP:

$\mathrm{LPV}_{i}=\mathrm{PVFF}_{\mathrm{i}}+\mathrm{PVL} L_{i}+\mathrm{PVMM}_{\mathrm{i}}+\mathrm{PVU}_{\mathrm{i}}$

$$
\begin{aligned}
\mathrm{LFP}_{i}= & 1000 \mathrm{LA}_{i} \\
& \times\left(\frac{\mathrm{fpm}}{1+(\mathrm{fpm}-\mathrm{fpi}) / \mathrm{fpi} \exp \left(-\left(\mathrm{rm}-\text { ra } \mathrm{AA}_{\mathrm{i}}\right) \mathrm{LPV}_{\mathrm{i}}\right)}-\mathrm{fpi}\right) .
\end{aligned}
$$

The selectivity parameter SP is an exponent applied to all these limiting factors, which expresses the strength of attractiveness of the patch on its frequentation by cattle: if $\mathrm{SP}=0$, then cattle distribution is uniform and only influenced by GSD; if $\mathrm{SP}=1$, then cattle tends to adjust the local utilization rate to the global utilization rate if the slope, the distance to water, the rock outcrops and the surrounding tree cover are null; if $\mathrm{SP}>1$, then cattle shows a high selectivity for the most attractive patches. In the first versions of WooDPAM, this selectivity parameter was fixed, but the last version assumes that it is negatively and exponentially linked to the global utilization rate:

$\mathrm{SP}=\operatorname{spm} \exp (-\mathrm{sps} \mathrm{GU})$

Eq. (34) is adapted from a logistic model, which expresses LFP $\left(\mathrm{kgDM} \mathrm{y}^{-1}\right)$ as a function of LPV, with a rate (coefficient of the exponent part) that depends on the apparent altitude AA. It includes four parameters: fpm is the maximum forage production ( $\mathrm{tDMha} \mathrm{h}^{-1} \mathrm{y}^{-1}$ ), fpi the 'initial' forage production for
In this expression, spm is the maximal value for SP and sps is a shape parameter. 


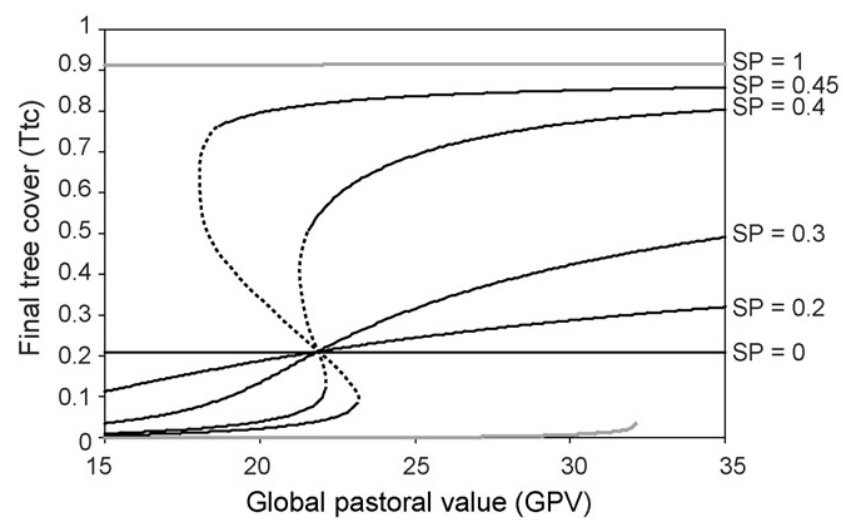

Fig. 3 - Bifurcation diagram of the patch submodel using the global pastoral value as control parameter with different fixed values of the selectivity parameter SP. Solid lines: stable equilibria (steady states); dashed lines: unstable equilibria. Unstable equilibria for $\mathrm{SP}=1$ are not represented on the graph.

To obtain the actual LSD, local stock densities in all patches are adjusted so that their weighted mean is equal to the global stock density GSD:

$\mathrm{LSD}_{i}=\mathrm{LSD} 1_{i} \frac{\mathrm{GSD} \sum_{j=1}^{n} \mathrm{LA}_{j}}{\sum_{j=1}^{n}\left(\mathrm{LSD} 1_{j} \mathrm{LA}_{j}\right)}$.

The local forage consumption LFC is the quantity of forage consumed by cattle in the patch yearly:

$\mathrm{LFC}_{\mathrm{i}}=\mathrm{LSD}_{\mathrm{i}} \mathrm{fc}_{\mathrm{LA}}$

The local utilization rate $\mathrm{LU}$ is the ratio between the local stock density and the local carrying capacity, or between the local forage consumption and the local forage production:

$\mathrm{LU}_{i}=\frac{\mathrm{LSD}_{i}}{\mathrm{LCC}_{i}}=\frac{\mathrm{LFC}_{i}}{\mathrm{LFP}_{i}}$

\subsection{The cattle submodel: cattle habitat use}

At the patch level, cattle activity influences vegetation dynamics through five auxiliary variables, ranging from 0 to 1 and quantifying grazing, browsing, dunging and trampling intensities.

Grazing intensity GI is simply the proportion of consumed forage in the herb layer:

$\mathrm{GI}_{\mathrm{i}}=\min \left(\mathrm{LU}_{\mathrm{i}}, 1\right)$

Browsing intensity of the species $s$ in the patch $i$ is the proportion of browsed tree saplings in the herb (BIh) or in the shrub (BIs) layer. It is positively related to local stock density, but negatively influenced by sapling density and facilitator synusiae (fallows or shrubs). Browsing intensity in the herb layer BIh depends on the local grazing intensity, on the cover of fallows and rock outcrops (facilitation effect) and on the total cover of saplings in the herb layer (density effect), with two parameters:

$\operatorname{BIh}_{s, i}=\mathrm{GI}_{i}^{b p_{s}}\left(1-F_{i}-\mathrm{RO}_{i}\right)\left(1-\right.$ msc Thc $_{\bullet}$ i $)$.

Browsing intensity in the shrub layer BIs depends on the local grazing intensity, on the cover of shrubs and rock outcrops (facilitation effect) and on the cover of saplings in the shrub layer (density effect), with the same two parameters:

$\mathrm{BIs}_{\mathrm{s}, \mathrm{i}}=\mathrm{GI}_{i}^{\mathrm{bp}} \mathrm{s}_{\mathrm{s}}\left(1-\mathrm{S}_{\mathrm{i}}-\mathrm{RO}_{\mathrm{i}}\right)\left(1-\mathrm{msc}_{\mathrm{Tsc}}, \mathrm{i}\right)$

In these two equations, the parameter $\mathrm{bp}_{\mathrm{s}}$ expresses the resistance of the tree species $s$ to browsing, ranging from 0.5 (high sensitivity) to 2 (high resistance). Parameter msc is the maximal proportion of non-browsed saplings whenever their cover is $100 \%$.

Dunging and trampling intensities are influenced by global stock density, tree cover, slope and watering places, as proved by recent observational studies (Kohler et al., 2006). The global dung density is the average density of dung pats deposed yearly by cattle in the whole paddock and is deduced from
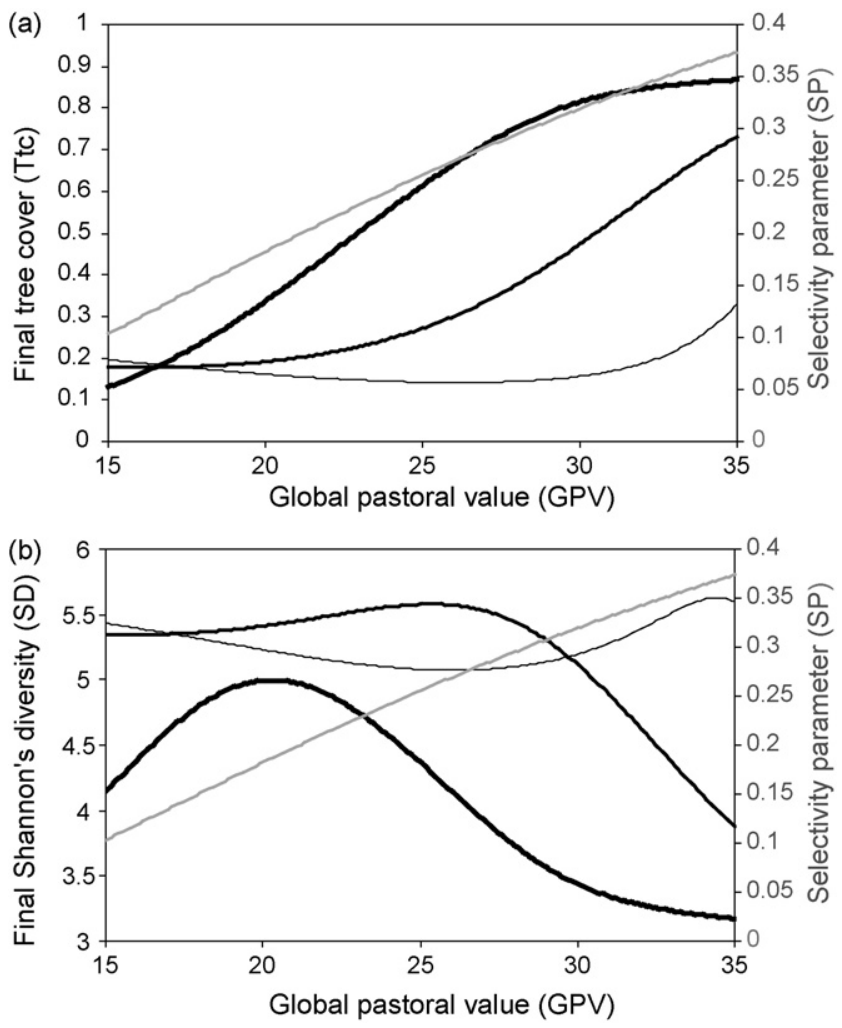

Fig. 4 - Bifurcation diagrams of the patch submodel with the selectivity parameter SP depending on the global pastoral value GPV. Solid black lines: stable equilibria for average values of slope $\mathrm{SL}=7.4^{\circ}$ and distance to water $\mathrm{DW}=218 \mathrm{~m}$ (lines with intermediate thickness), $\mathrm{SL}=0$ and $\mathrm{WD}=0$ (thin lines), or $\mathrm{SL}=30^{\circ}$ and $\mathrm{WD}=500 \mathrm{~m}$ (thick lines); grey lines: selectivity parameter, constant along each simulation run. (a) steady states for the overall tree cover; (b) steady states for the Shannon's diversity of the phytocoenosis. 

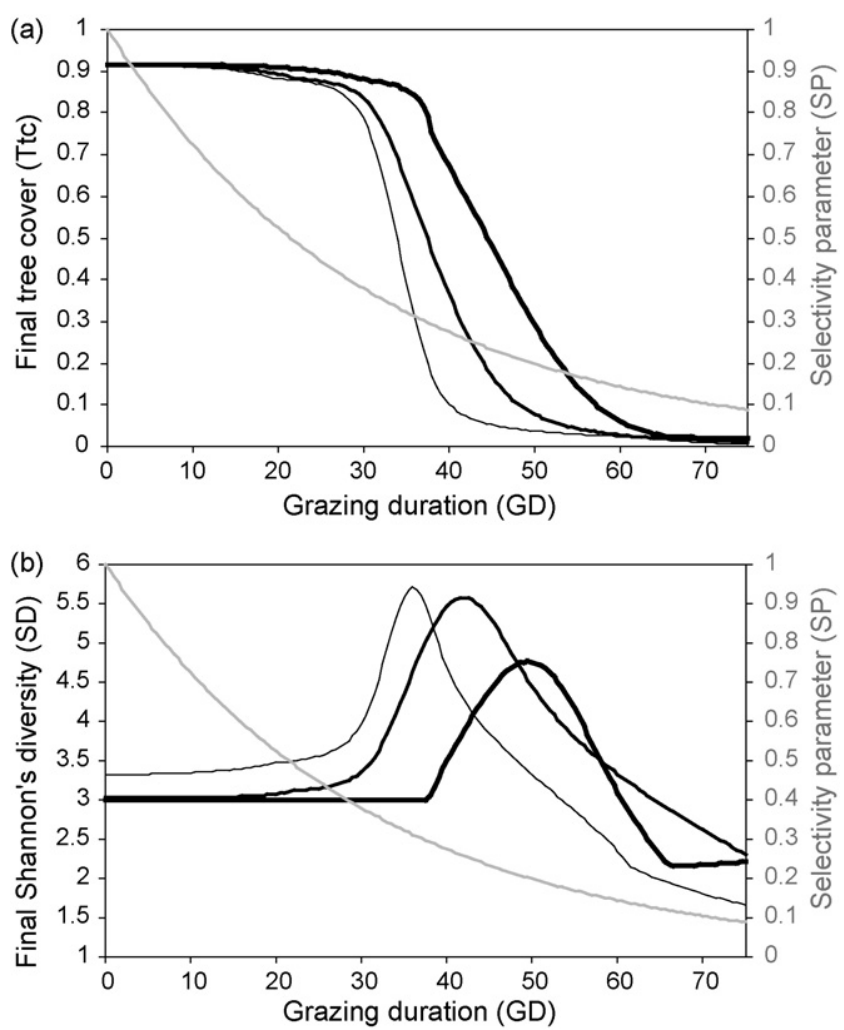

Fig. 5 - Bifurcation diagrams of the patch submodel with the selectivity parameter SP depending on the total duration of the grazing period GD (days). Solid black lines: stable equilibria for average values of slope $\mathrm{SL}=7.4^{\circ}$, distance to water $\mathrm{DW}=\mathbf{2 1 8} \mathrm{m}$ and rock outcrops $\mathrm{RO}=\mathbf{1 0} \%$ (lines with intermediate thickness), $\mathrm{SL}=0, \mathrm{WD}=0$ and $\mathrm{RO}=0$ (thin lines), or $\mathrm{SL}=30^{\circ}$ and $\mathrm{WD}=1000 \mathrm{~m}$ and $\mathrm{RO}=25 \%$ (thick lines); grey lines: selectivity parameter, constant along each simulation run. (a) steady states for the overall tree cover; (b) steady states for the Shannon's diversity of the phytocoenosis.

the average individual daily dung deposition DD:

GDD $=$ DD GSD

A first estimate of the local dung density LDD1 is calculated from GDD, taking into account tree cover, slope and distance to the nearest watering place:

$\mathrm{LDD}_{i}=\mathrm{GDD}\left(1-\mathrm{Ttc}_{\bullet}, \mathrm{i}\right)\left(1-\frac{\min \left(\mathrm{SL}_{i}, \text { slt }\right)}{\mathrm{slt}}\right) \sqrt{\frac{\mathrm{pwm}}{1+\mathrm{DW}_{\mathrm{i}} / \mathrm{dwt}}}$.

Then local dung densities in all patches are adjusted so that their weighted mean is equal to the global dung density GDD:

$\mathrm{LDD}_{i}=\mathrm{LDD}_{i} \frac{\mathrm{GDD} \sum_{j=1}^{n} \mathrm{LA}_{j}}{\sum_{j=1}^{n}\left(\mathrm{LDD} 1_{j} \mathrm{LA}_{j}\right)}$

Dunging intensity DI is the proportion of a maximal density of dung pats deposed annually on the patch mdd, that is the highest dung density usually observed in real systems:

$\mathrm{DI}_{\mathrm{i}}=\min \left(\frac{\mathrm{LDD}_{i}}{\mathrm{mdd}}, 1\right)$

Trampling intensity TI is the proportion of the patch area affected by trampling (flattened vegetation, compacted soil, gaps). It depends on local stock density, slope, tree cover and distance to water

$$
\begin{aligned}
\mathrm{TI}_{\mathrm{i}}= & \min \left(\frac{\min \left(\mathrm{SL}_{\mathrm{i}}, \mathrm{slt}\right)}{\mathrm{slt}}+\sqrt{\mathrm{Ttc}_{\bullet}, \mathrm{i}}\left(1-\sqrt{\mathrm{Ttc}_{\bullet}, \mathrm{i}}\right)\right. \\
& \left.+\left(\frac{\mathrm{pwm}}{1+\mathrm{DW}_{\mathrm{i}} / \mathrm{dwt}}\right)^{2}, 1\right)\left(1-\exp \left(d \mathrm{LSD}_{\mathrm{i}}\right)\right) .
\end{aligned}
$$

Eq. (51) expresses the commonly observed fact (Kohler et al., 2006) that trampling effects are increased by slope and are more important around water points and beneath isolated trees (i.e. in patches with a moderate tree cover).

All these local variables of the 'cattle' submodel influence the rates of change between compartments in the 'herb' or the 'wood' submodels, involving complex feedback loops.
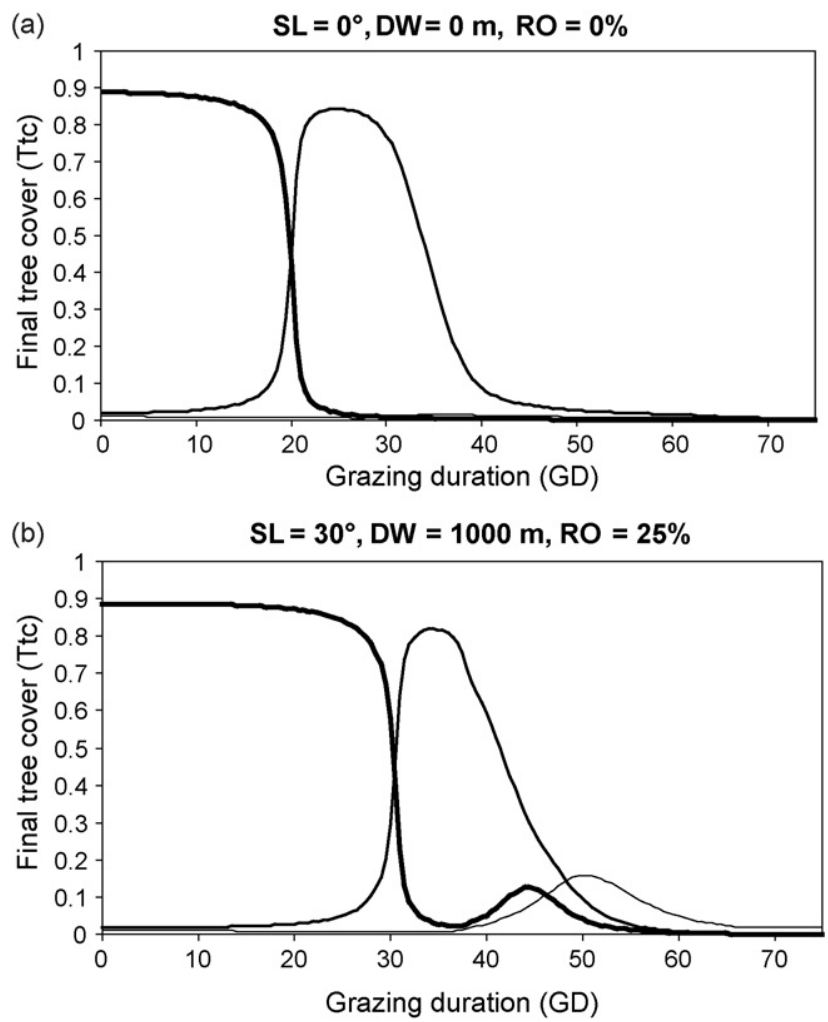

Fig. 6 - Bifurcation diagrams of the patch submodel with the selectivity parameter SP depending on the total duration of the grazing period GD (days). Solid black lines: stable equilibria for the tree cover of each species. Thick lines: Fagus sylvatica; lines with intermediate thickness: Picea abies; thin lines: Acer pseudoplatanus. (a) very attractive patch, $S L=0, W D=0$ and $R O=0$; (b) very repelling patch, $\mathrm{SL}=30^{\circ}, \mathrm{WD}=1000 \mathrm{~m}$ and $\mathrm{RO}=25 \%$. 


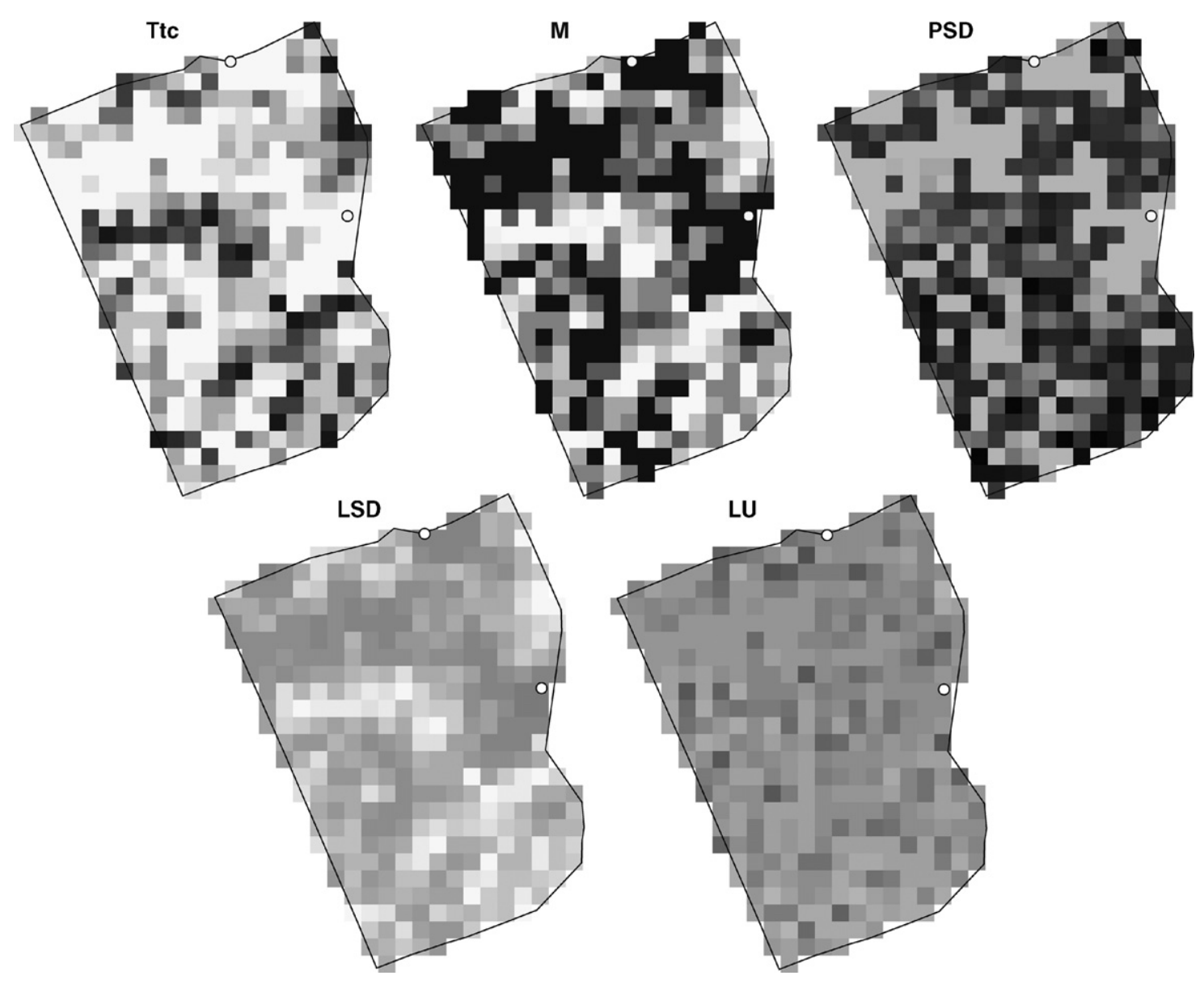

Fig. 7 - Maps of the initial configuration of the landscape mosaic. The paddock is subdivided into 393 cells of $25 \times 25 \mathrm{~m}^{2}$. Ttc: tree cover (0-1); M: meadows (0-1); PSD: Shannon's diversity of the phytocoenosis (1-6); LSD: local stock density (0-350); LU: local utilisation rate (0-1.6). Solid line: fence; white circles: watering places.

\subsection{Synthetic descriptors of vegetation diversity}

A diversity index SD of the phytoceonosis is calculated using Shannon's formula, from the local cover of the $p$ homoecies $H$ present in each patch $i$ (meadows, lawns, fallows, underwoods, shrub layer and tree layer):

$\mathrm{VC}_{i}=\mathrm{M}_{\mathrm{i}}+\mathrm{L}_{\mathrm{i}}+\mathrm{F}_{\mathrm{i}}+\mathrm{U}_{\mathrm{i}}+\mathrm{Sc}_{\mathrm{i}}+\mathrm{Ttc}_{\bullet}, i$

$\mathrm{SD}_{i}=\exp \left(-\sum_{k=1}^{p}\left(\frac{\mathrm{H}_{k, i}}{\mathrm{VC}_{i}} \ln \left(\frac{\mathrm{H}_{k, i}}{\mathrm{VC}_{\mathrm{i}}}\right)\right)\right)$.

The average Shannon's diversity PSDm of all patches included in the paddock provides a global assessment of the local synusial diversity:

$\operatorname{PSDm}=\frac{\sum_{i=1}^{n} \mathrm{SD}_{i}}{n}$

Phytocoenosis type is determined from the local total tree cover, according to the structural typology of Gillet and Gallandat (1996a, b), which distinguishes unwooded pastures (type 1: $0 \leq \mathrm{Ttc}<1 \%$ ), scarcely wooded pastures (type 2: $1 \% \leq \mathrm{Ttc}<20 \%$ ), densely wooded pastures (type 3 : $20 \% \leq$ Ttc $<70 \%$ ) and grazed forests (type $4: 70 \% \leq$ Ttc $\leq 100 \%$ ).

The number of patches $P_{j}$ belonging to each phytocoenosis type $j$ is used to calculate the Shannon's diversity SDI of the vegetation in the landscape:

$\mathrm{SDI}=\exp \left(-\sum_{j=1}^{m}\left(\frac{P_{j}}{n} \ln \left(\frac{P_{j}}{n}\right)\right)\right)$.

In this expression, $m$ is the number of phytocoenosis types present in the landscape $(1 \leq m \leq 4)$ and $n$ is the total number of patches.

\subsection{Parameter calibration}

Most processes in this model are described for the first time by equations, for which parameters were not available in the literature. However, most of them have a direct biological meaning allowing the use of published or unpublished estimates. Sources are referenced in Table 1.

Parameters of Eq. (34) were obtained from a nonlinear regression analysis of data from various sources (unpublished 
records in Switzerland), allowing the prediction of the annual forage production from the pastoral value and the altitude.

For the nine other parameters, whose source is referenced as 'Optimization' in Table 1, series of sensitivity analyses were performed to detect those which had the strongest influence on the behaviour of the patch model, using the 'batch runs' feature of Berkeley Madonna 8.0.1 (http://www.berkeleymadonna.com/). They were then adjusted empirically up to obtain realistic predictions from simple simulation experiments with the patch model and with the landscape model.

\subsection{Stability analyses with the patch submodel}

A first series of experiments was performed on the patch submodel, all global variables being fixed as parameters, in order to detect possible multiple attractors in the system of differential equations. For this purpose, a simplified model was designed and analysed using Berkeley Madonna.

In this model, I considered an isolated cell evolving towards equilibrium in a constant environment. The local and global parameters were adjusted so that local conditions were the same than the average conditions in the landscape, except for the control parameters chosen in each experiment. Average values for slope $\left(\mathrm{SLm}=7.4^{\circ}\right)$, distance to the nearest watering place ( $\mathrm{DWm}=218 \mathrm{~m}$ ), elevation $(\mathrm{Am}=\mathrm{AAm}=1216 \mathrm{~m})$, rock outcrops $(\mathrm{ROm}=10 \%)$ and overall tree cover $(\mathrm{Ttcm}=24.7 \%)$ were those observed in a real pasture-woodland landscape, a paddock of the Métairie d'Evilard in the Swiss Jura Mountains (Kohler et al., 2006). The global stock density GSD was fixed to 89.6 ABU d ha ${ }^{-1} \mathrm{y}^{-1}$ (GS = 49.2 ABU, GD $=42 \mathrm{dy}^{-1}$, total area $=23.063 \mathrm{ha}$ ), which corresponded to the cattle load applied in year 2001 for the rotational management of this paddock (Perrenoud et al., 2003).

A stability analysis was performed using the 'parameter plot' feature of Berkeley Madonna, starting from various initial conditions for the state variables and applying different values of GPV (used as parameter) from 15 to 35 by intervals of 0.1. Attractors were found by reporting the final value of the local tree cover Ttc after simulations runs of 10,000 years (Euler method, $d t=1$ year). Since analytical methods could not apply to this complex system of equations, unstable equilibria were searched with help of the boundary value solver of Berkeley Madonna, by setting two equal boundary conditions for Ttc at time 2000 and 4000 and solving for GPV and initial Ttc. Since this empirical method does not make it possible to find all unstable equilibria, only some points were located and used to rebuild the curve by interpolation.

This stability analysis was applied to two versions of the patch submodel: in the first version, the selectivity parameter SP was fixed and independent from the global utilization rate GU; in the second version, a feedback between GU and SP was added according to Eq. (40).

A second stability analysis was carried out with the last version of the patch submodel to explore the response at long term of tree cover and Shannon's diversity to the global stock density in various local environmental conditions. For this, I used the grazing duration GD as control parameter (all other global parameters being maintained constant), with 151 simulation runs of 10,000 years for GD varying from 0 to 75 days by intervals of 0.5 . The global pastoral value was fixed to the average value measured in the paddock $(\mathrm{GPV}=25.12)$.

\subsection{Scenario experiments with the mosaic model}

A last series of experiments was carried out with the full mosaic model built in the Simile visual modelling environment. A simple version was used for optimization purposes, with a low number of cells and simple gradients for the environmental variables. It will not be presented here.

WoodPAM was finally applied to a concrete example of pasture-woodland landscape, the Métairie d'Evilard. In this mosaic model, patches corresponded to the 393 cells of a paddock described in a recent observational study (Kohler et al., 2006), for which detailed data were available for vegetation, environment (natural and management-induced structures) and cattle activity. The situation of year 2001 was used to set up the management and initial conditions of the system in the model.

A first scenario was tested with no climate change $(C C=0)$, so that environmental and management constraints were fixed to their initial values, including apparent altitude. In a second scenario, I considered a very optimistic climate change by setting up CC to $1.2^{\circ} \mathrm{C}$ per century, in order to observe the gradual effect of the decreasing apparent altitude over 600 years.

All simulations were performed using Euler method with $\mathrm{dt}=1$ year, after having verified that the results were not affected by a change in the integration method (Runge-Kutta 4 ) and the time step $(d t=0.1)$.

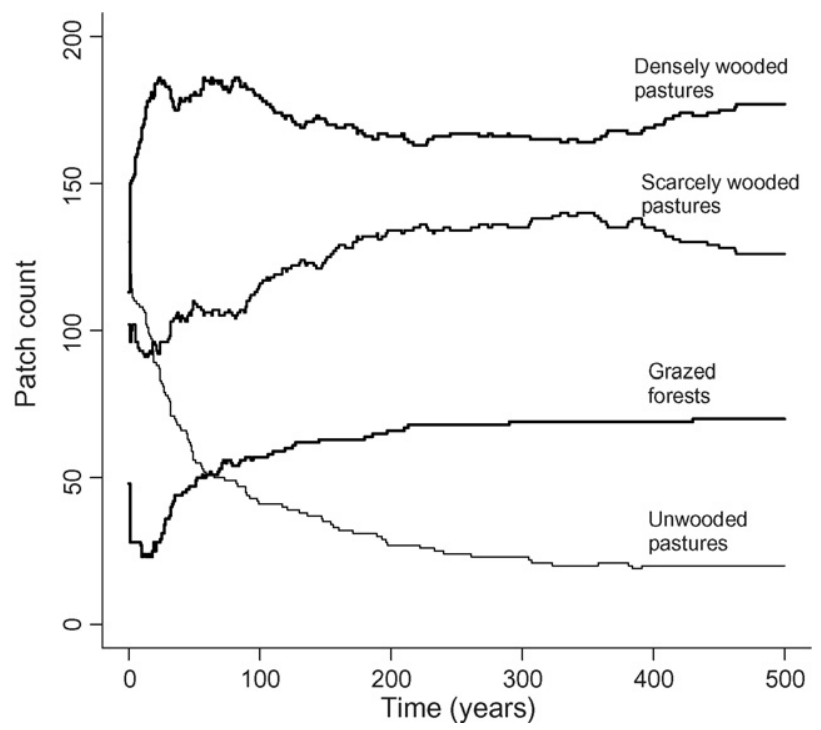

Fig. 8 - Simulation of the dynamics of the landscape mosaic in a pasture-woodland with all global environmental and management conditions fixed to their initial values: changes in the number of cells classified in each phytocoenosis type. Very thin line: unwooded pastures; thin line: scarcely wooded pastures; thick line: densely wooded pastures; very thick line: grazed forests. 

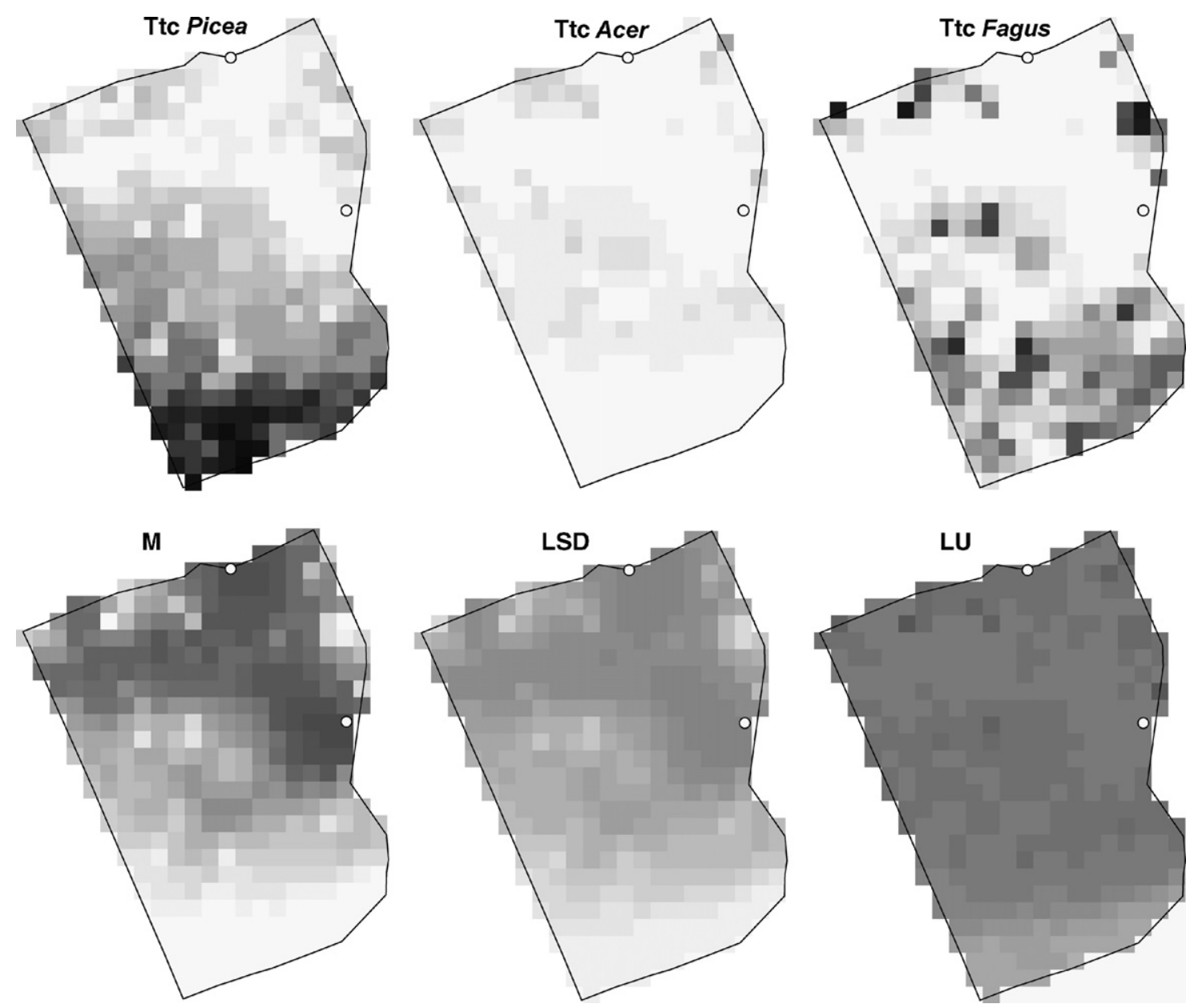

Fig. 9 - Maps of the landscape mosaic at the end of a 500-year simulation with all global environmental and management conditions fixed to their initial values. Ttc: local tree cover of Picea abies, Acer pseudoplatanus and Fagus sylvatica (0-1); M: meadows (0-1); LSD: local stock density (0-350); LU: local utilisation rate (0-1.6). Solid line: fences; white circles: watering places.

\section{Results}

\subsection{Stability analysis of the patch submodel}

In a first experiment, the selectivity parameter SP was fixed and independent from the global utilization rate GU. A parameter graph (Fig. 3) shows the result of this stability analysis for a global pastoral value ranging from 15 to 35, i.e. for a global utilization rate GU ranging from about $91 \%$ to $39 \%$. If SP is set to 0 , the final tree cover, about $21 \%$, is independent from the global pastoral value because in this case the local stock density is always equal to the global stock density. This stable equilibrium depends only on the global and local parameters of the environment: global stock density, global tree cover, slope, distance to water and altitude. For low values of SP (e.g., 0.2 or 0.3), attractors form a continuous sigmoid curve. From $\mathrm{SP} \approx 0.38$, a two-fold bifurcation occurs and the system became multistable: depending on the initial conditions, there may be two steady states for a same value of the control parameter around 22 , their two basins of attraction being delimited by an unstable equilibrium. In this domain of global instability (e.g., for
$18.65<\mathrm{GPV}<23.1$ if SP $=0.45$ ), a tree cover between 10 and $75 \%$ would be very difficult to maintain at long term. The size of this domain of instability increases dramatically with the selectivity parameter: for $\mathrm{SP}=1$, the system is driven by two extreme steady states, a closed forest and an open pasture, throughout most of the range of the control parameter. All these curves intersect at a single pivot point corresponding to the singular state where LSD =GSD. For the chosen set of parameters, it corresponds to the boundary between scarcely and densely wooded pastures, in which Shannon's diversity is high. However, this common equilibrium point can be an attractor or a repellor depending on the selectivity parameter: the higher the selectivity, the lower the local stability around this point.

In a second experiment, the feedback between GU and SP was set up according to Eq. (40). Parameters were chosen so as to obtain a wide range of possible tree cover at equilibrium. Therefore, the selectivity parameter SP, ranging from ca. 0.1 to 0.4 , was constant over time but dependent on the global pastoral value used as parameter in the stability analysis (Fig. 4). The system is now globally stable: the attractors are not sensitive anymore to the initial conditions. The shape of the equilibrium curve depends on the local configuration of 


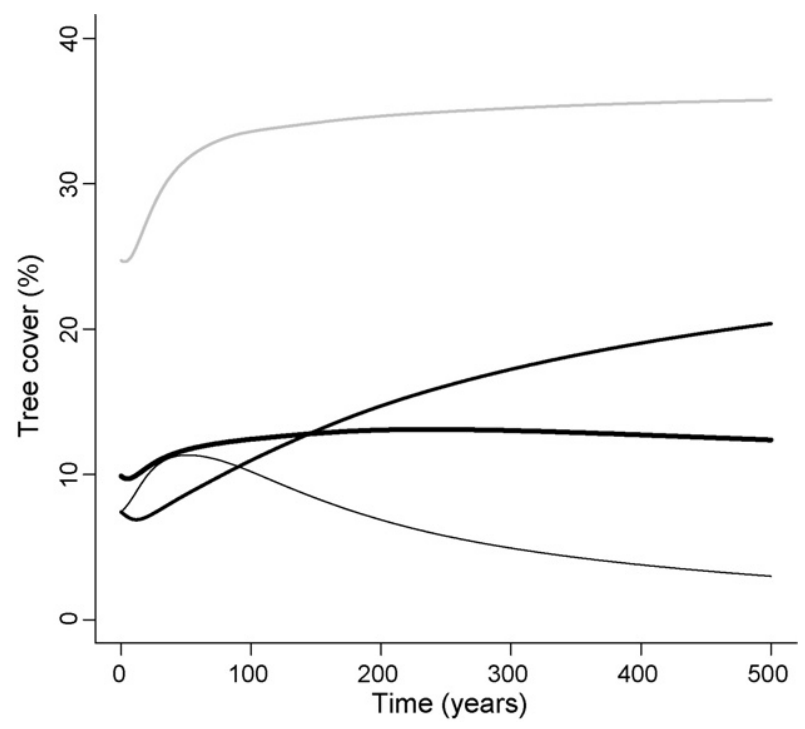

Fig. 10 - Simulation of the dynamics of the tree species in a pasture-woodland with all global environmental and management conditions fixed to their initial values: changes in the local cover of Picea abies, Acer pseudoplatanus (thin line) and Fagus sylvatica (thick line) in the tree layer. Grey line: total tree cover.

the environment. If the local environmental parameters correspond to the average values observed in the paddock, as in the first experiment, then the balanced tree cover varies between 18 and $72 \%$, with a minimum value for GPV $\approx 17.5$. The Shannon's diversity of the phytocoenosis is at highest for GPV $\approx 25.5$ and decreases dramatically for higher values of the control parameter. If the patch is very attractive for cattle, i.e. a flat area close to the watering place and without rock outcrops, the maximum tree cover is about $30 \%$ and the minimum is about $14 \%$ at GPV $\approx 26$. Shannon's diversity is always high, with a maximum around GPV $\approx 34.5$. Finally, in an unfavourable situation, i.e. on a steep slope far from water and with many rock outcrops, final tree cover ranges from $13 \%$ to $87 \%$ and Shannon's diversity presents a symmetrical bell shape with a maximum at $\mathrm{GPV} \approx 20.5$.

In a third experiment using the same model (with SP depending on GU), I performed another stability analysis to explore the response at long term of tree cover and Shannon's diversity to the grazing duration in various local environmental conditions (Fig. 5). The global utilization rate ranges here from 0 to 1 and the selectivity parameter from 1 to 0.1 . In all cases, the system seems globally stable: no hysteresis effect appeared in the simulations. The final tree cover at equilibrium responds to grazing duration following a sigmoid curve, whose shape depends on the local site conditions: in the most attractive configuration, the inflexion point is lower and the slope at this point is very high. The maximum Shannon's diversity is higher in this case but the peak of the curve is narrower.

What is the respective role of the three tree species in these steady state configurations? Fig. 6 shows the final tree cover of Fagus, Picea and Acer for the two extreme situations. At very long term, the most competitive species, Fagus syl- vatica, is largely dominant at lowest grazing pressure. It is replaced by the most browsing-resistant species, Picea abies, at medium grazing pressure, whereas the post-pioneer Acer pseudoplatanus is only dominant in the steep ground situation and for a high grazing pressure. The transition between Fagusdominated and Picea-dominated domains along the grazing gradient is very narrow in both cases: little variations in the stocking rate, around 20 days for the first situation or around 30 days for the second, will lead to a dramatic switch in species composition of the tree layer.

\subsection{Simulation experiments on the mosaic model}

In the next experiments, the mosaic model was applied to a real system. The initial configuration is very heterogeneous and fine-grained (Fig. 7). However, because of the relatively low stocking rate (GU $\approx 55 \%$ ), the local utilization rate is more homogeneously distributed in the landscape.

If environmental and management constraints are fixed to their present state, including apparent altitude $(C C=0)$, the simulated landscape changes rapidly during the first decades, with a decrease of unwooded pastures and grazed forests, and an important increase of densely wooded pastures (Fig. 8). This first adaptation phase suggests that the initial vegetation was far to be in balance with the management conditions applied to the paddock in 2001. From about 25 years after the beginning of the simulation, scarcely wooded pastures and grazed forests increase whereas densely wooded pastures tend to stabilize and unwooded pastures continue decreasing slowly. After a long evolution of about 500 years, the landscape configuration seems to reach an equilibrium, although minor transformations occur at very long term (even after 3000 years). The final

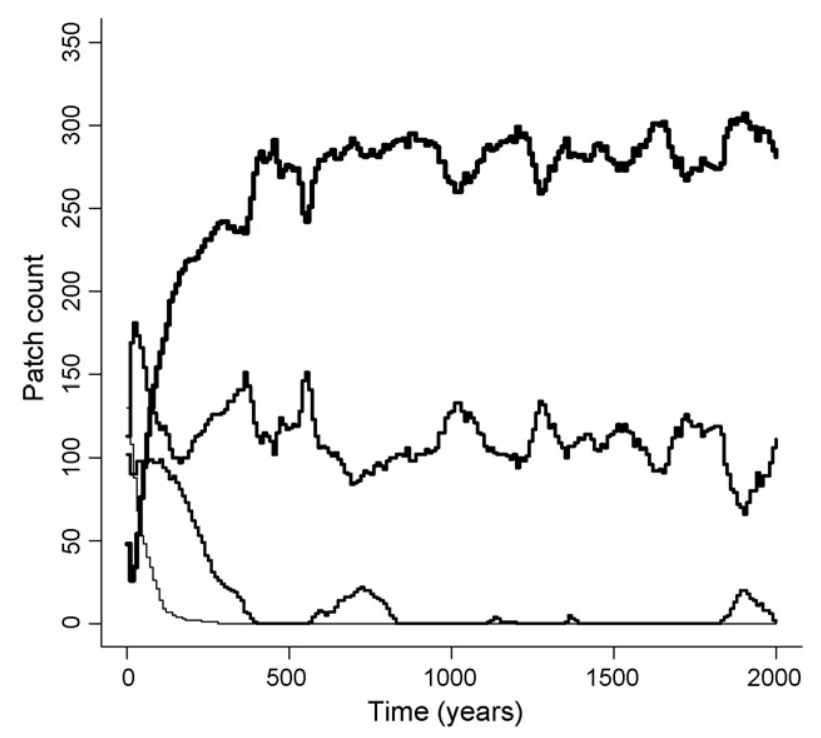

Fig. 11 - Simulation of the effect of a linear temperature increase of $1.2^{\circ} \mathrm{C}$ per century on the dynamics of the landscape mosaic in a pasture-woodland: changes in the number of cells classified in each phytocoenosis type. Very thin line: unwooded pastures; thin line: scarcely wooded pastures; thick line: densely wooded pastures; very thick line: grazed forests. 
configuration is dominated by densely and scarcely wooded pastures.

However, the spatial distribution of the phytocoenoses is far less irregular than the initial configuration and depends more strictly on the local environmental variables, such as altitude, slope, rock outcrops and distance to water. Trees are mainly abundant in the southern part of the paddock, with lower altitude, higher mean slope and far from the watering places (Fig. 9). Productive meadows tend to concentrate in flat areas not too far from water. The local stock density and the local utilization rate, although still homogeneously distributed, are lower in the southern part.

The slowest dynamics is due to growth processes in the tree layer (Fig. 10): after a slight decrease in the first decades, the overall tree cover Ttcm increases from $25 \%$ to $35 \%$, due to the fast dynamics of Acer pseudoplatanus, which is progressively replaced by Fagus sylvatica and Picea abies, the latter becoming dominant 150 years after the beginning of the simulation. This slow evolution is not achieved after 500 years.

However, landscape dynamics being very slow, realistic predictions must take into account the effect of global warming. If a regular temperature increase is applied $\left(C C=1.2^{\circ} \mathrm{C}\right.$ per century), the simulation shows that climate change has a dramatic effect on long-term vegetation dynamics (Fig. 11). The first adaptation phase is similar to this of the previous simulation, but from about 50 years, densely wooded pastures decrease and grazed forests increase to become rapidly dominant, whereas unwooded and scarcely wooded pastures tend to disappear. After 400 years, grazed forests and densely wooded pastures tend to oscillate irregularly around an average value and scarcely wooded pastures reappear at some periods.

At a simulation time of 500 years, the landscape configuration is heterogeneous and quite different of the initial configuration (Fig. 12).

The apparent altitude stops decreasing after 600 years when it reaches the sea level and thus the global environment becomes invariant. However, the dynamics remains unstable forever. This is due to a continuous change in the spatial configuration of the landscape, as shown by the comparisons of the maps obtained at a simulation time of 1800, 1900 and 2000 years (Fig. 13). The local environment conditions are no longer constraining the patterns of local stock density or tree cover. Moreover, irregular cycles characterize the dynamics in each patch.
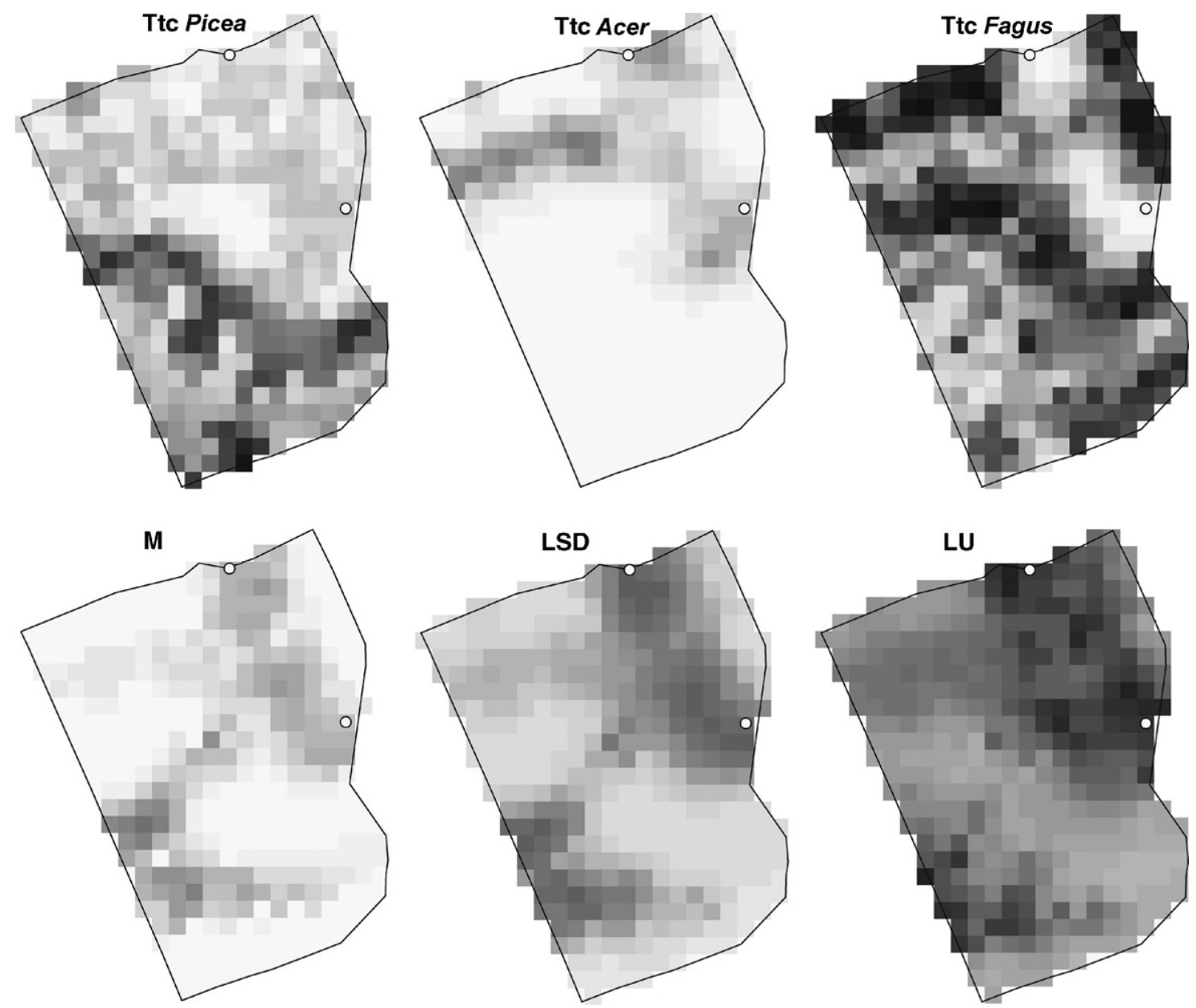

Fig. 12 - Maps of the landscape mosaic at the end of a 500-year simulation with a linear temperature increase of $1.2{ }^{\circ} \mathrm{C}$ per century. Ttc: local tree cover of Picea abies, Acer pseudoplatanus and Fagus sylvatica (0-1); M: meadows (0-1); LSD: local stock density (0-350); LU: local utilisation rate (0-1.6). Solid line: fences; white circles: watering places. 

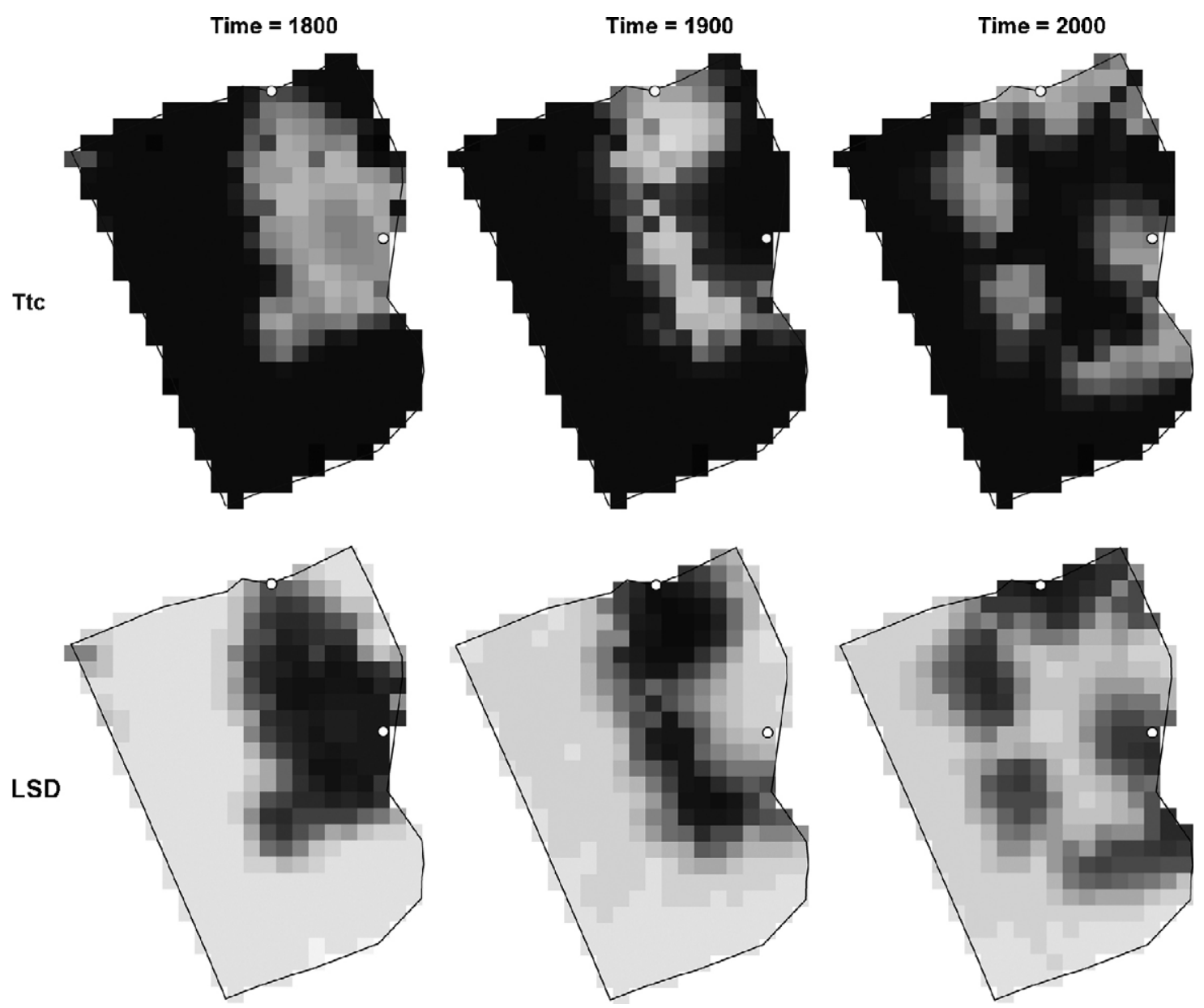

Fig. 13 - Maps of the landscape mosaic at the end of a 1800-2000-year simulation with a linear temperature increase of $1.2^{\circ} \mathrm{C}$ per century. Ttc: local total tree cover (0-1); LSD: local stock density (0-350). Solid line: fences; white circles: watering places.

From 500 years, the total tree cover of the paddock remains around $80 \%$ (Fig. 14). Acer pseudoplatanus completely disappears after 1300 years and Fagus sylvatica becomes the dominant species from 400 years, by progressively outcompeting Picea abies in the grazed forests.

Starting from 0.55 , the global utilization rate increases rapidly during the early adaptation phase before fluctuating between 0.7 and 0.8 after the simulated temperature increase, whereas it tends asymptotically to ca. 0.7 if climate change is ignored (Fig. 15). This results in a low selectivity parameter, less than 0.2.

Concerning the two indices of vegetation diversity, the differences between the two scenarios are important (Fig. 16). The mean Shannon's diversity of the phytocoenoses at patch level tends to decline over time from the initial conditions, but the decrease is far more dramatic if climate change is taken into account. By contrast, the Shannon's diversity of the landscape, based on the phytocoenosis types, tends to increase rapidly during the initial adaptation phase before remaining high in the static scenario, whereas it declines up to its initial value in the warming scenario.

\section{Discussion}

\subsection{Equilibrium and grazing ecology}

Simulation models based on optimal foraging theory have been useful for quantifying some underlying behavioural mechanisms of spatial grazing patterns of livestock (Bailey et al., 1998). However, these models did not pay attention to the processes of vegetation dynamics and their feedback with livestock activities. They focus on spatial processes at a fine time resolution, incompatible with the time scale considered in WoodPAM.

The question of equilibrium in pastures is generally addressed without consideration of spatial heterogeneity (Milchunas et al., 1988; Westoby et al., 1989; Briske et al., 2003; Cingolani et al., 2005). Moreover, the interactions between forest dynamics, grassland dynamics and herbivore habitat use are generally ignored, since most studies focus on rather homogeneous open pastures.

Recently, a synthetic theoretical model of grazing effects on rangeland diversity was proposed (Cingolani et al., 2005), 


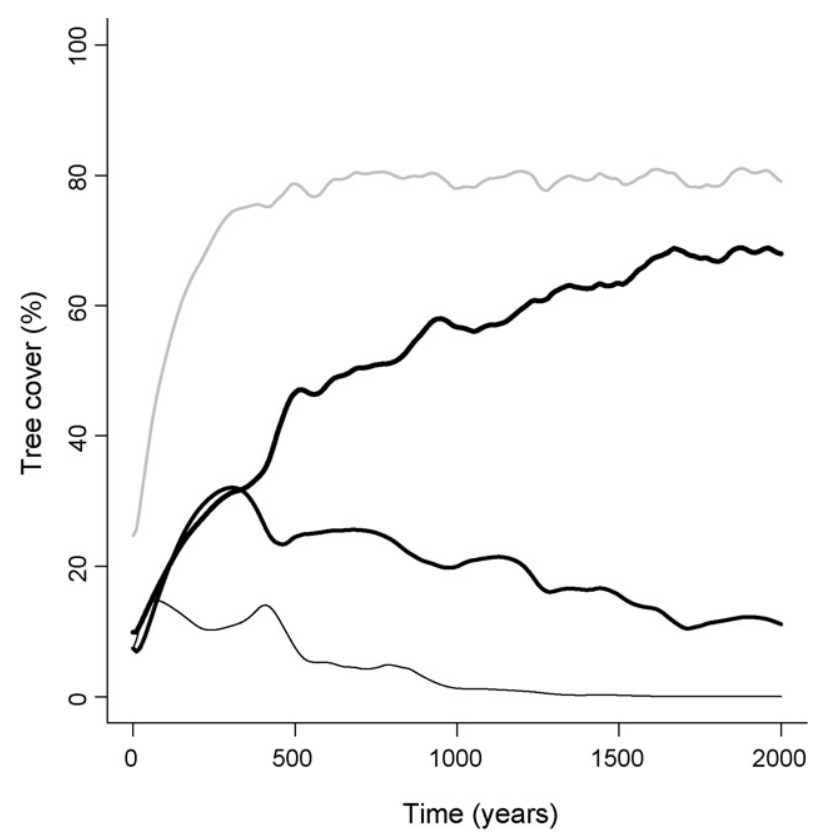

Fig. 14 - Simulation of the dynamics of the tree species in a pasture-woodland with a linear temperature increase of 1.2 ${ }^{\circ} \mathrm{C}$ per century: changes in the local cover of Picea abies, Acer pseudoplatanus (thin line) and Fagus sylvatica (thick line) in the tree layer. Grey line: total tree cover.

which links plant diversity and community structure to grazing intensity taking into account productivity (resource availability, stress conditions) and evolutionary history of grazing. The authors argued that for ecosystems with a long history of grazing, stable equilibria were expected because of resilience mechanisms allowing reversible changes. However, this theory does not apply to heterogeneous wooded landscapes, in which various dynamics interfere at different time and space scales. Neither the classical 'range succession model' (Dyksterhuis, 1949; Westoby et al., 1989) nor the contemporary 'modified MSL model' (Cingolani et al., 2005) are

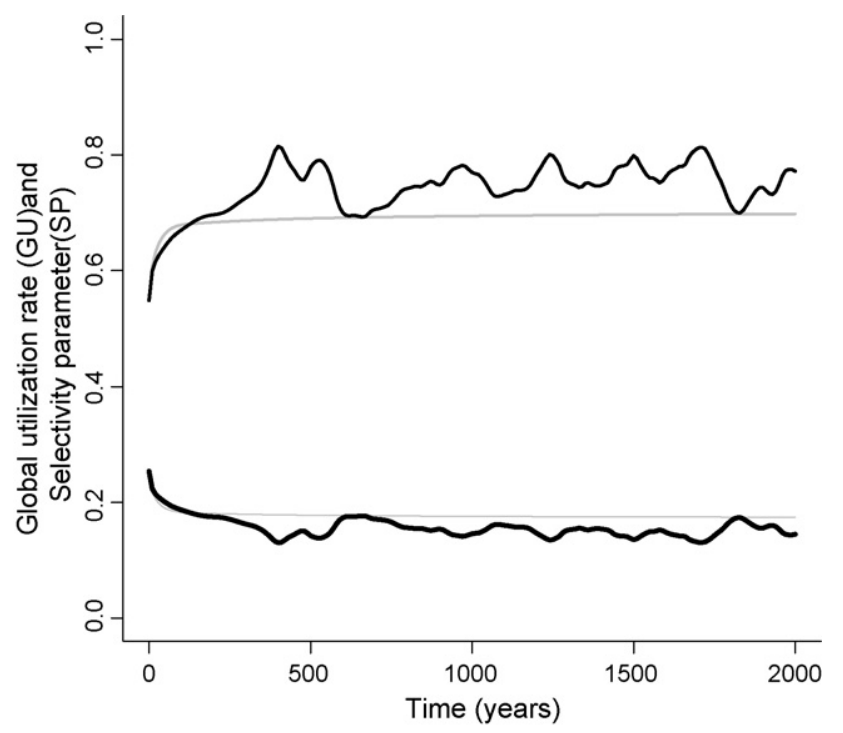

Fig. 15 - Evolution of the global utilization rate GU (thin lines, top) and of the selectivity parameter SP (thick lines, bottom) in a pasture-woodland with or without a linear temperature increase of $1.2^{\circ} \mathrm{C}$ per century. Black lines: warming scenario; grey lines: static scenario.

relevant for mountain silvopastoral ecosystems, characterized by a long evolutionary history of grazing and heterogeneous resource availability.

The simulation experiments with WoodPAM suggest that it is quite impossible for spatial patterns of vegetation and cattle habitat use to reach a stable equilibrium within a reasonable time, i.e. compatible with management decisions: even after long simulation runs of 10,000 years, patterns are still changing. This is due to the hierarchical organization of the system, to the possible existence of multiple basins of attraction at fine scale, and to the influence of external changing constraints, such as climate change. Moreover, in real systems, episodic disturbances, such as droughts, hurricanes or insect
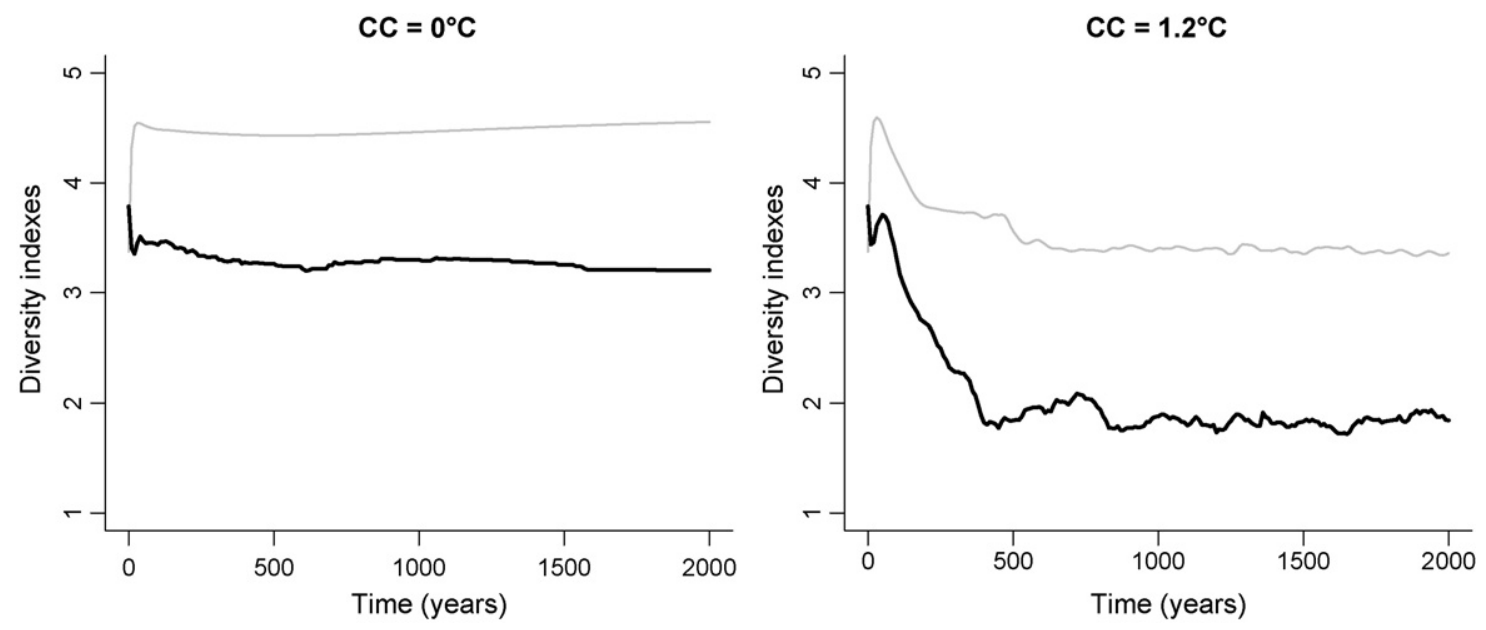

Fig. 16 - Evolution of the Shannon's diversity of the landscape SDI (black lines) and of the mean Shannon's diversity of the patches PSDm (grey lines) in a pasture-woodland with (right) or without (left) a linear temperature increase of $1.2^{\circ} \mathrm{C}$ per century. 
outbreaks, make the occurrence of any stable equilibrium even very improbable.

\subsection{Shifting mosaic and cyclic dynamics}

According to the theory of 'shifting mosaics' (Olff et al., 1999; Bakker et al., 2004), the key process contributing to spatial diversity in vegetation structure of grazed woodlands is the alternation of plant facilitation and competition. This process occurring at fine scale should lead to cyclic dynamics involving shifting mosaics of grasslands, shrub thickets and trees. However, there is no observational evidence for such cyclic dynamics in mountain spruce-dominated woodpastures: trees generally regenerate in the same place and only directional successions have been reported.

In close connection with this theory is the 'wood-pasture' hypothesis (Vera, 2000; Bradshaw et al., 2003; Kirby, 2004; Birks, 2005; Mitchell, 2005), according to which the former natural forest in European lowlands was a mosaic of large open and closed areas driven by large herbivores. Moreover, this mosaic was the result of a long cyclic evolution involving three stages: park, scrub and grove.

There was little evidence from my simulation experiments for a cyclic evolution in vegetation patches, as predicted by the shifting mosaic theory or the wood-pasture hypothesis. Nevertheless, WoodPAM includes most processes that are invoked by the authors of these theories: facilitation (protection by unpalatable herbs and shrubs), competition (crowding and shading effects), light requirements and resistance to grazing of the tree species, etc. Cyclic successions occurred only with some combinations of parameters and under certain conditions, such as these illustrated by the warming scenario. Interestingly, this scenario corresponds precisely to the traditional domain of application of these theories: a woodland-dominated landscape with a relatively high grazing pressure at low altitude.

\section{Conclusion}

The model was able to explain some aspects of the origin of vegetation heterogeneity in silvopastoral ecosystems. It revealed the crucial role of livestock selectivity on the consequences of complex interactions between landscape structure, vegetation and cattle behaviour. It provided a demonstration of the necessity to consider the hierarchical organization of the ecosystem to model long-term dynamics. It emphasized the instability of the landscape mosaic and the great influence of climate change. Therefore, it fulfilled the strategic objectives for which it was designed.

Of course, many limitations can be pointed out. WooDPAM is based on several strong assumptions and simplifications and its optimization was tricky. The mosaic model appeared very sensitive to certain combinations of parameters, in particular those applied to tree species. Moreover, validation is known to be a rather difficult task in ecological modelling, especially with landscape models and long-term simulations, for which long time series of observations are generally missing. Therefore, a lot of work remains to be done.
Episodic events could play an important role in landscape dynamics of pasture woodland and their incorporation in WoodPaM should be a promising improvement. Since the purpose of this model was to explore the attractors of the hierarchical system, no stochastic processes were included. However, if a more tactic than strategic perspective is considered, accurate predictions should require (1) more time series and data from field experiments to improve the calibration of the model; (2) the introduction of stochastic processes, in particular for an individual-based modelling of tree mortality and growth; (3) the introduction of some control variables for the simulation of management practices (fertilizing, timbering, etc.); and (4) a more detailed formalization of climate change taking into account inter-annual variability and extreme events on a stochastic basis. Long-term simulations taking into account climate change may lead to realistic predictions of pasture-woodland landscape dynamics under various management scenarios and disturbance regimes.

WooDPAM could be easily adapted to reconstruct the past evolution of wooded areas under the grazing pressure of wild large herbivores in lowlands. This should provide some insight in the debate about the role of grazing in the structure and dynamics of primeval forests.

\section{Acknowledgements}

This work was supported by the Swiss National Science Foundation, NCCR Plant Survival.

\section{REFERENCES}

Bailey, D.W., Dumont, B., Wallis De Vries, M.F., 1998. Utilization of heterogeneous grasslands by domestic herbivores: theory to management. Annales de Zootechnie 47, 321-333.

Bakker, E.S., Olff, H., Vandenberghe, C., De Maeyer, K., Smit, R., Gleichman, J.M., Vera, F.W.M., 2004. Ecological anachronisms in the recruitment of temperate light-demanding tree species in wooded pastures. Journal of Applied Ecology 41, 571-582.

Balent, G., Alard, D., Blanfort, V., Gibon, A., 1998. Grazing systems, landscape patterns and biodiversity. Annales de Zootechnie 47, 419-429.

Barbezat, V., 2002. Aspects forestiers du zonage et de la dynamique du taux de boisement en pâturage boisé jurassien. Ph.D. thesis, ETHZ, Zürich, Switzerland.

Birks, H.J.B., 2005. Mind the gap: how open were European primeval forests? Trends in Ecology and Evolution 20, 154-156.

Bradshaw, R.H.W., Hannon, G.E., Lister, A.M., 2003. A long-term perspective on ungulate-vegetation interactions. Forest Ecology and Management 181, 267-280.

Briske, D.D., Fuhlendorf, S.D., Smeins, F.E., 2003. Vegetation dynamics on rangelands: a critique of the current paradigms. Journal of Applied Ecology 40, 601-614.

Cingolani, A.M., Noy-Meir, I., Diaz, S., 2005. Grazing effects on rangeland diversity: a synthesis of contemporary models. Ecological Applications 15, 757-773.

Costanza, R., Voinov, A. (Eds.), 2004. Landscape Simulation Modeling-A Spatially Explicit, Dynamic Approach. Springer, New York, p. 330.

Dyksterhuis, E.J., 1949. Condition and management of rangeland based on quantitative ecology. Journal of Range Management 2, 104-115. 
Ellenberg, H., Weber, H.E., Düll, R., Wirth, V., Werner, W., Paulissen, D., 1991. Zeigerwerte von Pflanzen in Mitteleuropa. Scripta Geobotanica, Göttingen.

Etienne, M. (Ed.), 1996. Western European Silvopastoral Systems. INRA Editions, Paris, France, p. 276.

Gillet, F., Gallandat, J.D., 1996a. Integrated synusial phytosociology: some notes on new, multiscalar approach to vegetation analysis. Journal of Vegetation Science 7, 13-18.

Gillet, F., Gallandat, J.D., 1996b. Wooded pastures of the Jura mountains. In: Etienne, M. (Ed.), Western European Silvopastoral Systems. INRA Editions, Paris, France, pp. 37-53.

Gillet, F., Besson, O., Gobat, J.M., 2002. PATUMOD: a compartment model of vegetation dynamics in wooded pastures. Ecological Modelling 147, 267-290.

Kirby, K.J., 2004. A model of a natural wooded landscape in Britain as influenced by large herbivore activity. Forestry 77, 405-420.

Kohler, F., Gillet, F., Gobat, J.M., Buttler, A., 2004. Seasonal vegetation changes in mountain pastures due to simulated effects of cattle grazing. Journal of Vegetation Science 15, 143-150.

Kohler, F., Gillet, F., Reust, S., Wagner, H.H., Gadallah, F., Gobat, J.M., Buttler, A., 2006. Spatial and seasonal patterns of cattle habitat use in a mountain wooded pasture. Landscape Ecology 21, 281-295.

Landolt, E., 1977. Ökologische Zeigerwerte zur Schweizer Flora. Veröff. geobot. Inst. Rübel 64, 1-208.

Milchunas, D.G., Sala, O.E., Lauenroth, W.K., 1988. A generalized model of the effects of grazing by large herbivores on grassland community structure. American Naturalist 132, 87-106.
Mitchell, F.J.G., 2005. How open were European primeval forests? Hypothesis testing using palaeoecological data. Journal of Ecology 93, 168-177.

Muetzelfeldt, R., Massheder, J., 2003. The Simile visual modelling environment. European Journal of Agronomy 18, 345-358.

Olff, H., Vera, F.W.M., Bokdam, J., Bakker, E.S., Gleichman, J.M., de Maeyer, K., Smit, R., 1999. Shifting mosaics in grazed woodlands driven by the alternation of plant facilitation and competition. Plant Biology 1, 127-137.

O'Neill, R.V., DeAngelis, D., Waide, J., Allen, T.F.H., 1986. A Hierarchical Concept of Ecosystems. Princeton University Press, Princeton, 235.

Pauli, H., Gottfried, M., Grabherr, G., 1996. Effects of climate change on mountain ecosystems-upward shifting of alpine plants. World Resource Review 8, 382-390.

Perrenoud, A., Känzig-Schoch, U., Schneider, O., Wettstein, J.B., 2003. Exploitation Durable des Pâturages Boisés. Un Exemple Appliqué du Jura Suisse. Haupt, Zürich, Switwerland.

Rebetez, M., 1999. Twentieth century trends in droughts in southern Switzerland. Geophysical Research Letters 26, 755-758.

Vera, F.W.M., 2000. Grazing Ecology and Forest History. CABI, Wallingford.

Westoby, M., Walker, B., Noy-Meir, I., 1989. Opportunistic management for rangelands not at equilibrium. Journal of Range Management 42, 266-274.

Wu, J., David, J.L., 2002. A spatially explicit hierarchical approach to modeling complex ecological systems: theory and applications. Ecological Modelling 153, 7-26. 